\title{
A dinâmica da taxa de câmbio em países emergentes: uma perspectiva pós-keynesiana sobre os casos de Brasil e México entre 2000 e $2017^{*}$
}

The dynamics of exchange rates in emerging countries: a post-Keynesian perspective for the cases of Brazil and Mexico between 2000 and 2017

\author{
Nathalie Marins ${ }^{\dagger}$ \\ Daniela Prates ${ }^{\ddagger}$
}

\begin{abstract}
Resumo
Na perspectiva pós-keynesiana, a taxa de câmbio é considerada um tipo de ativo financeiro sujeito às decisões de alocação de portfólio dos agentes que atuam em um sistema monetário e financeiro internacional hierárquico e assimétrico. Baseado nesta perspectiva, este artigo realiza um estudo de caso comparativo das taxas de câmbio do Brasil e do México nos anos 2000, destacando a influência de fatores institucionais. $O$ estudo cobre seis fases do ciclo financeiro internacional e utiliza o Método de Média Móvel Exponencial e o coeficiente de Pearson para analisar a relação entre as taxas de câmbio e os determinantes da equação keynesiana. Os resultados mostram que, embora as taxas de câmbio estudadas tenham um comovimento semelhante, existem diferenças importantes em relação à sua volatilidade e ao impacto desses determinantes.
\end{abstract}

Palavras-chave: Taxa de câmbio; economia keynesiana; América Latina

\begin{abstract}
In the post-Keynesian view, the exchange rate is considered a financial asset class subject to investment decisions of investors in a hierarchical and asymmetric international monetary and financial system. Based on this theoretical reference, this paper conducts a comparative case study of the exchange rates of Brazil and Mexico during the 2000s. The goal is to highlight the influence of institutional on the exchange rate dynamics. The study covers six phases of the international liquidity cycle, using the Exponentially Weighted Moving Average method and the Pearson coefficient. The results show that, although the exchange rates studied have a very similar co-movement, there are important differences regarding their volatility and the impact of the theoretical determinants.
\end{abstract}

Keywords: Exchange rate; keynesian economics; Latin America

JEL Classification: F31; F33; E1.

\footnotetext{
* Agradecimentos: $O$ presente trabalho foi realizado com apoio do Conselho Nacional de Desenvolvimento Científico e Tecnológico (CNPq) - Processo: 134011/2015-5

+ Doutoranda em Economia na Universidade Estadual de Campinas. E-mail: nathalie.marins@gmail.com

₹ Professora associada do Instituto de Economia da UNICAMP e pesquisadora nível 1 do CNPq. Email: danimagaprates@gmail.com
} 


\section{Introdução}

A taxa de câmbio é considerada, ao lado da taxa de juros e de salários, um dos principais preços-chave de uma economia aberta. Porém, a sua dinâmica tem sido um campo de intensa controvérsia entre economistas de diferentes perspectivas teóricas.

Na perspectiva pós-keynesiana, as taxas de câmbio nominais possuem, em geral, um padrão cíclico no curto prazo, resultado das mudanças na alocação de portfólio dos agentes que atuam no sistema monetário e financeiro internacional contemporâneo (SMFIC). Esta literatura também destaca que as economias emergentes ${ }^{1}$, em especial, possuem um comportamento caracterizado por uma maior volatilidade potencial e maior vulnerabilidade às pressões de depreciação nas fases de baixa no ciclo de liquidez internacional, e de apreciação nas fases de alta. Essa dinâmica específica é estudada por meio da equação da taxa de juros própria keynesiana que inclui, além do diferencial de juros, o diferencial de liquidez das suas moedas (e a preferência dada pelos agentes a este atributo) e o grau de abertura financeira de cada país.

Contudo, a heterogeneidade existente entre as economias emergentes permite levantar a hipótese ainda pouco explorada na literatura de que elementos particulares, como a institucionalidade da abertura financeira, a dimensão (e regulação) dos seus mercados cambiais e o regime cambial também podem, dentro de certos limites, afetar a dinâmica das taxas de câmbio destes países. Assim, este artigo procura contribuir para literatura existente explorando a relação entre os determinantes gerais da dinâmica cambial na perspectiva pós-keynesiana e esses elementos mediante um estudo comparativo entre as taxas de câmbio do Brasil (real/dólar) e do México (peso/dólar) nos anos 2000.

A escolha desses países baseou-se num dos critérios de escolha de amostra em pesquisas comparativas em ciências sociais, denominado most similar case (Collier, 1993; George \& Bennet, 2005). Brasil e México podem ser considerados casos similares não somente por serem economias emergentes com uma inserção similar no SMFIC, mas também por duas razões adicionais: (ii) são países latinoamericanos com perfis econômicos semelhantes em termos de tamanho das suas economias, grau de industrialização, relevância do setor exportador e graus de integração financeira e de internacionalização monetária; (ii) no que se refere às políticas macroeconômicas, ambos adotaram regimes de flutuação suja com metas de inflação após as crises cambiais dos anos 1990.

\footnotetext{
${ }^{1} \bigcirc$ termo "países emergentes" refere-se aos países periféricos (ou em desenvolvimento) que se inseriram no processo de globalização financeira (Prates, 2015).
} 
O trabalho está dividido em cinco seções, além desta introdução. Enquanto a segunda seção apresenta, em linhas gerais, a abordagem de determinação cambial pós-keynesiana, a terceira resume as características institucionais das aberturas comercial e financeira, do mercado de câmbio e do regime cambial dos dois países. Já a quarta seção realiza um estudo dos determinantes das taxas de câmbio mexicana e brasileira por meio do coeficiente de correlação de Pearson e pelo método EWMA (Exponentially Weighted Moving Average). Por último, as conclusões são apresentadas.

\section{A abordagem Pós-Keynesiana da taxa de câmbio}

O argumento central da teoria pós-keynesiana de determinação da taxa de câmbio desenvolvida por Schulmeister (1987) e Harvey (2009) é que os preços relativos entre duas moedas são função das decisões de alocação de portfólio dos investidores internacionais, sendo que as expectativas sobre a rentabilidade financeira futura das aplicações denominadas em cada moeda que guiam estas decisões. Incorporando este argumento e elementos da abordagem estruturalista, alguns autores debruçaram-se sobre a dinâmica diferenciada do preço relativo das moedas emitidas por países emergentes resultado das assimetrias monetária e financeira do SMFI contemporâneo.

Conforme apontado por Prates (2002) e Andrade e Prates (2013), a assimetria monetária se refere ao caráter hierárquico do sistema monetário internacional, organizado em torno de uma moeda-chave, o dólar fiduciário no sistema atual, que cumpre todas as funções monetárias (unidade de conta, meio de pagamento e reserva de valor) no plano internacional e, assim como a moeda nacional em uma economia fechada, possui o maior prêmio de liquidez em âmbito mundial (liquidez da divisa). As moedas emitidas pelos demais países centrais estão em posição intermediaria e também são líquidas, mas em menor grau do que a moeda-chave. Já as moedas dos países emergentes se encontram no piso desta hierarquia pois, de forma geral, não exercem as funções da moeda fora das suas fronteiras nacionais e, consequentemente, não são consideradas líquidas em âmbito internacional. Já a assimetria financeira possui duas dimensões. A primeira se refere à natureza dos fluxos que se direcionam aos países emergentes, que dependem de uma dinâmica exógena a esses países. Já a segunda diz respeito a sua participação marginal nos fluxos de capitais globais que, apesar de residual, são elevados relativamente ao tamanho dos seus mercados (Prates, 2002, p. 171).

Levando estas assimetrias em consideração, o modelo de escolha de ativos, elaborado por Keynes no capítulo 17 da sua Teoria Geral, tem sido utilizado por 
diversos autores pós-keynesianos para estudar a dinâmica cambial dos países emergentes.

Para Andrade e Prates (2013), no caso dos ativos negociados nos mercados cambiais, há quatro atributos que determinam o seu retorno total: i) a apreciação esperada $a$; ii) a taxa de rendimento $q$ do investimento realizado; iii) o atributo $c$ que se refere aos custos de uma aplicação em determinada moeda de modo que, quanto maior o grau de abertura financeira, menor será este custo e; iv) o prêmio não pecuniário $l$, que reflete a liquidez da divisa e possui um caráter mais estrutural que os demais fatores. Todos estão denominados na moeda-chave do sistema.

Na equação 1, na qual as variáveis com asteriscos são os atributos da moedachave do sistema, ao calcular o retorno esperado relativo, os agentes passam a direcionar a demanda para o ativo (moeda) que apresentar o maior rendimento esperado, elevando seu preço:

$$
r=(q-c)+a+l=\left(q^{*}-c^{*}\right)+l^{*}
$$

Em equilíbrio, definido como uma situação de repouso ${ }^{2}$, e considerando a apreciação esperada como a diferença entre a taxa à vista no período $t\left(s_{t}\right)$ e a taxa à vista esperada para o período $t+1\left(s_{t+1}^{e}\right)$, a dinâmica das taxas de câmbio dos países pode ser analisada com base na equação 2 :

$$
s_{t}=s_{t+1}^{e}+\left(q^{*}-q\right)+\left(l^{*}-l\right)-\left(c^{*}-c\right)
$$

Assim, nesta perspectiva, dadas as assimetrias do SMFIC, a demanda dos não-residentes por uma determinada moeda periférica sofre importante influência de condicionantes externos. Ou seja, como as moedas das economias emergentes não funcionam como reserva de valor (possuem um $l$ estruturalmente baixo) em âmbito internacional, a sua demanda passa a estar condicionada aos ciclos de fluxos de capitais e às variações esperadas nos atributos $a, q$ e $c$. Em períodos de excesso de liquidez (e baixa preferência pela liquidez) internacional, quando há maior disposição dos investidores internacionais a formar posições em ativos mais arriscados, os ativos emergentes se tornam objeto de desejo pois há uma expectativa de apreciação e/ou uma perspectiva de ganhos de capital que compensam a menor liquidez da divisa. Já nas fases em que há uma maior preferência pela liquidez, esses ativos são as primeiras vítimas da "fuga para a

\footnotetext{
2 É adotada a hipótese de Kaltenbrunner (2015) de equalização dos retornos, que não necessariamente será atingido.
} 
qualidade" dos investidores internacionais exatamente por não funcionarem como reserva de valor e, portanto, não são um receptáculo de incerteza em escala global (Andrade e Prates, 2013 p. 401).

Buscando explicitar a diferença entre os condicionantes estruturais e conjunturais, Ramos (2016 p. 115 -116) propõe a incorporação da variável $\beta$ que mede a importância atribuída pelos investidores ao prêmio de liquidez. Incorporando essa variável à equação 2 , a equação 3 aponta que um aumento no $\beta$ deve levar a um aumento na depreciação esperada, caso o diferencial de juros não diminua

$$
s_{t}=s_{t+1}^{e}+\left(q^{*}-q\right)+\beta\left(l^{*}-l\right)-\left(c^{*}-c\right)
$$

Desse modo a dinâmica das taxas de câmbio dos países analisados neste trabalho será realizada com base na Equação $3^{3}$. Contudo, além destes componentes e da dinâmica externa do ciclo de liquidez internacional, a institucionalidade da abertura financeira, a dimensão (e regulação) dos seus mercados cambiais e o regime cambial que condicionam os fluxos de capitais e as posições nos mercados de derivativos também podem, dentro de certos limites, afetar a dinâmica das taxas de câmbio. A próxima seção analisa estes condicionantes para os países selecionados.

\section{Condicionantes específicos da dinâmica cambial no Brasil e no México}

Esta seção apresenta as características institucionais de cada país. Enquanto a primeira subseção realiza uma comparação das respectivas integrações (comercial e financeira) com o resto do mundo, a segunda é destinada à comparação dos mercados de câmbio. Já a terceira subseção apresenta o formato institucional de regime de câmbio flutuante em cada país.

\subsection{Abertura comercial e financeira}

grau de abertura comercial se refere à facilidade com que as trocas comerciais entre os países são realizadas, ou seja, quanto maiores as restrições vigentes a essas trocas, menor será esse grau. Já o grau de abertura financeira é definido como: "(...) the degree of the ease with which residents can acquire assets and liabilities denominated in foreign currencies and non residents can operate in national financial markets" (Akyüz, 2014 p. 37). Nessa definição, a abertura pode

\footnotetext{
${ }^{3}$ A melhor forma de medir e modelar as expectativas ainda é um tema em aberto nesta abordagem (Ramos e Prates, 2018), de modo que estas não foram consideradas de forma direta neste trabalho.
} 
ser caracterizada em três níveis: i) inward transactions, que se refere à entrada de recursos externos no país; ii) outward transactions, que se relaciona à transferência de recursos para o exterior por parte de residentes e o endividamento de nãoresidentes no mercado doméstico e; iii) conversibilidade interna da moeda externa, ou seja "allowing debtor-creditor relations among residents in foreign currencies." (Ibid, p. 37). Quanto maior for o grau de abertura financeira, maior a probabilidade de predominância dos fluxos financeiros relativamente aos fluxos comerciais e, assim da influência das decisões de portfólio dos investidores globais, subordinadas à uma lógica especulativa, sobre a trajetória da taxa de câmbio nominal.

No Brasil, enquanto o primeiro nível de abertura financeira havia sido atingido já no início dos anos 2000, o segundo nível praticamente se completou na década seguinte, sendo a principal proibição remanescente o endividamento de não residentes ${ }^{4}$. Já o terceiro nível da abertura continua limitado. Apenas um número restrito de agentes tem direito de manter contas em moeda estrangeira no mercado financeiro doméstico que não são de movimentação livre (Prates, 2015).

Porém, as alterações no marco regulatório que viabilizaram a ampliação do grau de abertura financeira da economia brasileira ocorreram por meio de circulares do Banco Central do Brasil (BCB) e resoluções do Conselho Monetário Nacional $(\mathrm{CMN})$ sem discussão no Congresso Nacional. Além disso, conforme apontado por Prates (2015, p. 63), essa abertura foi feita sem alteração da Lei no 4.131 de 1961, que regulamenta os capitais estrangeiros, o que significa que "o governo brasileiro tem o direito de impor controles cambiais sobre qualquer conta do balanço de pagamentos", como os adotados entre 2010 e 2011. Neste período, o Brasil passou a implementar regulações sobre os fluxos de capitais (controles de capitais e regulação prudencial) e sobre os derivativos cambiais que afetaram o custo de captação externa, dos investimentos em portfólio no país e das posições vendidas nos mercados de câmbio à vista e para liquidação diferida. Em 2009, por exemplo, foram implementados IOF sobre as aplicações de não residentes em renda fixa e de portfólio, que foram elevados em 2010. Já em 2011 o IOF se estendeu para as captações de empréstimos externos. Nesse mesmo ano também houve mudanças nas regras de recolhimento de compulsório sobre as posições vendidas em câmbio dos bancos (regulamentação prudencial). A primeira regulação sobre os derivativos foi adotada em 2010, mas a principal foi a imposição de IOF sobre as posições

\footnotetext{
${ }^{4}$ Esta restrição é caracterizada como uma medida de controle anti-especulação por Mohanty e Scatigna (2005) uma vez que este endividamento aumenta a vulnerabilidade externa, ao ampliar o tamanho das apostas especulativas contra a moeda nacional.
} 
vendidas em derivativos cambiais acima de US\$ 10 mil em meados de 2011. Contudo, essas regulações que começaram a ser relaxadas em 2012, foram suprimidas em junho de 2013 (Prates, 2015). Por outro lado, a abertura comercial começou a ganhar força durante a década de 1990 quando muitas das barreiras não tarifarias foram abolidas. Contudo, a economia brasileira ainda é considerada relativamente fechada tanto de jure como de facto (OCDE, 2015).

No México, a abertura comercial e financeira, que já havia se iniciado na década de 1980 como consequência da crise da dívida externa de 1982, foi aprofundada com a chegada de Salinas de Gortari (1989-1994) ao governo. As principais medidas foram a promulgação da Lei de Mercados Mobiliários em 1989 e a assinatura do Tratado de Livre Comércio da América Do Norte (NAFTA, pela sigla em inglês), que entrou em vigor em 1994. A assinatura desse Tratado institucionalizou e generalizou a abertura comercial para quase todos os setores da economia mexicana, além de aumentar a mobilidade de capitais entre os países membros para garantir a possibilidade de repatriação dos investimentos realizados (Correa, 2014). Além disso, em maio de 1994, ao se tornar membro da Organização para a Cooperação e Desenvolvimento Econômico (OCDE) o México aceitou, entre outras, a obrigação de implementar o código de liberalização de movimentos de capitais. Com essas iniciativas, o México se tornou uma das economias mais abertas do mundo (Tornell e Martínez, 2003). Ademais, como a abertura financeira se deu com reformas na legislação, alterando a constituição, a imposição de regulações sobre os fluxos de capitais se tornou mais difícil do que no caso brasileiro.

Assim, as principais reformas em direção à completa liberalização das transações do primeiro e segundo nível de abertura financeira, assim como a abertura comercial, já haviam sido realizadas no início da década de 1990. Já o terceiro nível de abertura financeira, apesar não foi concluído. Apenas algumas categorias de agentes (em maior número que no Brasil) têm acesso a contas em dólares que incluem as empresas localizadas próximas à fronteira, as representações oficiais de governos estrangeiros, organismos internacionais e pessoas físicas estrangeiras que prestem serviços a essas instituições.

Assim, atualmente a abertura financeira nos dois primeiros níveis é similar em ambos os países, sendo a principal diferença a restrição para o endividamento de não residentes no Brasil e um maior grau de conversibilidade interna da moeda estrangeira no México (Tabela 1). 
Tabela 1. Características do grau de abertura financeira

\begin{tabular}{|c|c|c|}
\hline & México & Brasil \\
\hline $\begin{array}{l}\text { Primeiro nível } \\
\text { de abertura: } \\
\text { Inward } \\
\text { transactions }\end{array}$ & $\begin{array}{l}\text { Mercado de ações/propriedade: Não residentes estão } \\
\text { autorizados a participar em quase todos os setores. Ainda há } \\
\text { restrições para o controle (aquisição de mais de } 49 \% \text { das } \\
\text { ações) em alguns setores como, por exemplo os setores de } \\
\text { transporte e mídia. } \\
\text { Títulos públicos: Não residentes estão autorizados a } \\
\text { participar } \\
\text { Títulos de dívida privada (renda fixa): Não residentes } \\
\text { estão autorizados a participar } \\
\text { Captações externas: Entidades locais estão autorizadas a } \\
\text { obter financiamento offshore tanto por dívida bancária como } \\
\text { por emissão de títulos. Emissão de ações em bolsas } \\
\text { estrangeiras também está permitido. }\end{array}$ & $\begin{array}{l}\text { Mercado de ações/propriedade: Não residentes estão } \\
\text { autorizados a participar em uma ampla gama de setores. } \\
\text { Ainda há restrições para o controle de estrangeiros em } \\
\text { alguns setores como, por exemplo, no setor de mídia e } \\
\text { transporte. } \\
\text { Títulos públicos: Não residentes estão autorizados a } \\
\text { participar } \\
\text { Títulos de dívida privada (renda fixa): Não residentes } \\
\text { estão autorizados a participar } \\
\text { Captações externas: Entidades locais estão autorizadas a } \\
\text { obter financiamento offshore tanto por dívida bancária } \\
\text { como por emissão de títulos. Emissão de ações em bolsas } \\
\text { estrangeiras também está permitido. }\end{array}$ \\
\hline $\begin{array}{l}\text { Segundo nível } \\
\text { de abertura: } \\
\text { Outward } \\
\text { transactions }\end{array}$ & $\begin{array}{l}\text { Agentes nacionais estão autorizados a reter ativos externos, } \\
\text { sem restrições. } \\
\text { Não há restrições pra o endividamento de não residentes em } \\
\text { território nacional } \\
\text { Não há restrições para a repatriação de capital } \\
\text { Receitas de exportações não precisam ser repatriadas }\end{array}$ & $\begin{array}{l}\text { Agentes nacionais estão autorizados a reter ativos externos, } \\
\text { sem restrições. } \\
\text { Endividamento de não residentes no mercado doméstico } \\
\text { não é permitido } \\
\text { Receitas de exportações não precisam ser repatriadas }\end{array}$ \\
\hline $\begin{array}{c}\text { Terceiro nível } \\
\text { de abertura: } \\
\text { Conversibilida- } \\
\text { de interna da } \\
\text { moeda }\end{array}$ & $\begin{array}{l}\text { Contas em dólar estão autorizadas para pessoas jurídicas, } \\
\text { representações oficiais de governos estrangeiros, } \\
\text { organismos internacionais e pessoas fisicas estrangeiras que } \\
\text { prestem serviços a estas instituições. } \\
\text { Apenas bancos tem autorização para receber depósitos em } \\
\text { moeda estrangeira } \\
\text { Pagamentos em moeda estrangeira estão autorizadas. } \\
\text { Não há proibição para a abertura de contas no exterior } \\
\text { denominadas em moeda nacional }\end{array}$ & $\begin{array}{l}\text { Contas em dólar estão autorizadas para poucos participantes } \\
\text { e são de movimentação restrita. } \\
\text { Apenas bancos autorizados pelo BCB podem receber estes } \\
\text { depósitos } \\
\text { Pagamentos em moeda estrangeira não podem ser utilizados } \\
\text { (não possuem validade legal) } \\
\text { Abertura de contas no exterior em moeda nacional não é } \\
\text { permitida }\end{array}$ \\
\hline
\end{tabular}

Em relação à abertura comercial, a diferença entre o Brasil e o México é maior. De acordo com os dados de importação e exportação do Banco Mundial, o grau de abertura do comércio brasileiro está, desde a década de 1960, abaixo de outros países da América Latina e de países de renda média. Já o México é uma das economias mais abertas nesses grupos de países.

Gráfico 1. Indicador de abertura comercial (X+M/PIB)

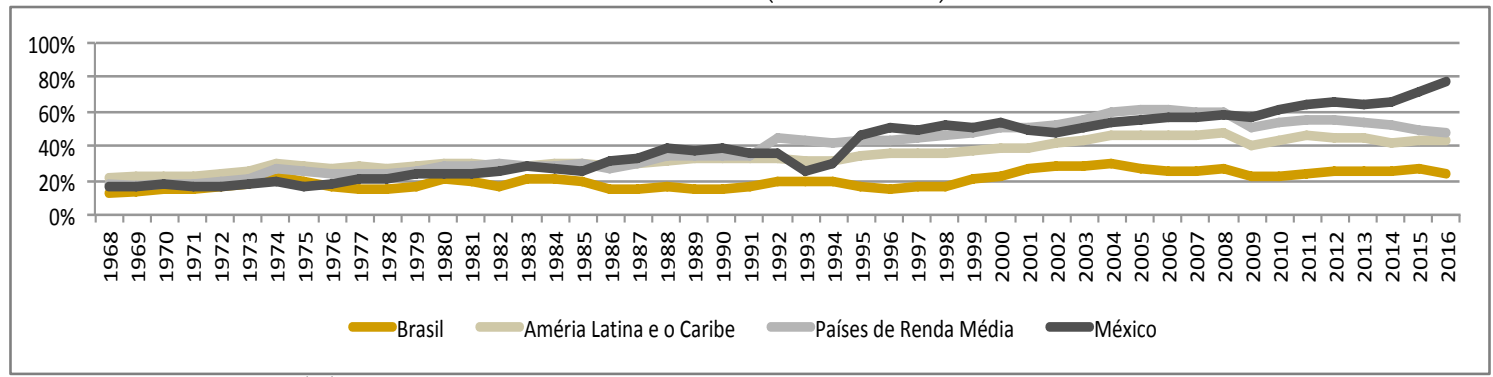

Fonte: BM (2019). Elaboração própria

No que se refere à pauta exportadora brasileira, observa-se um aumento relevante das exportações de produtos primários a partir dos anos 2000 (ver Gráfico 1). Isto tem levado alguns autores, como Kohlscheen (2014) a caracterizarem a moeda brasileira como uma moeda commodity pela alta correlação encontrada 
entre o aumento dos preços desses produtos e a apreciação cambial. Contudo, para Gallagher e Prates (2016), a influência dos preços das commodities na taxa de câmbio brasileira teria se dado por um "canal indireto" relacionado às expectativas de apreciação do real no mercado de derivativos, do que pelo ingresso efetivo de divisas proveniente de uma conta comercial superavitária em função das exportações de commodities. Neste sentido, o Brasil seria um caso de uma "financeirização da doença holandesa".

Gráfico 2. Participação dos produtos exportados

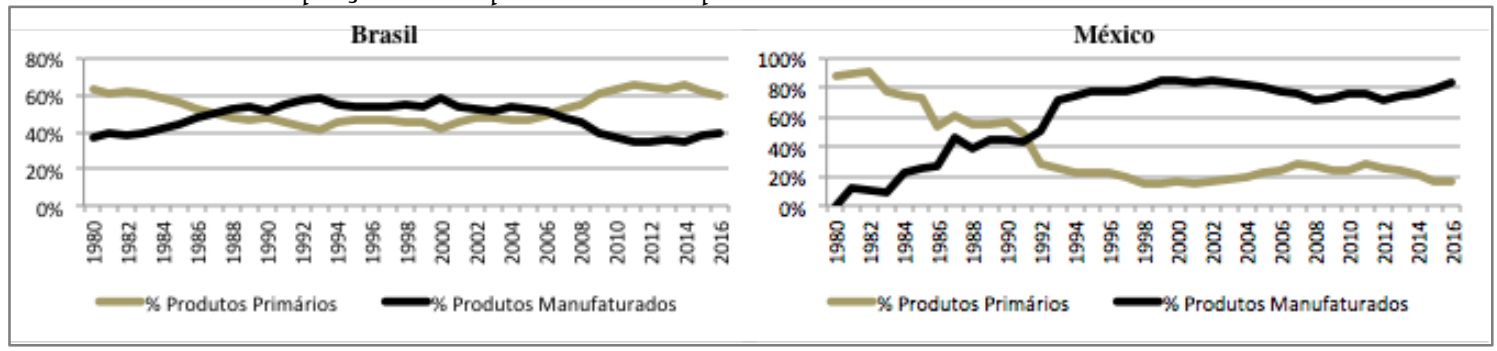

Fonte: Cepalstat (2019). Elaboração própria.

O México, por outro lado, é menos dependente das exportações de commodities do que o Brasil, mas as exportações relacionadas ao petróleo ainda contribuem de forma significativa para o crescimento do PIB mexicano (OCDE, 2017), além de ainda serem uma fonte relevante de ingresso de moeda estrangeira. Em contrapartida, as manufaturas exportadas pelo México, que representam mais de $80 \%$ da sua pauta comercial, estão relacionadas às indústrias "maquiladoras", que realizam operações de montagem com um baixo conteúdo local, o que tem contribuído para aumentar os déficits comercial e em transações correntes do país.

\subsection{Institucionalidade do mercado de câmbio e internacionalização monetária}

Esta seção adota o conceito de institucionalidade do mercado de câmbio definido por Prates (2015 p. 61), como "o conjunto de regras que disciplinam o funcionamento do mercado de câmbio em cada um dos seus segmentos (à vista e de derivativos)". Assim, a caracterização dessa institucionalidade está condicionada à abertura financeira e diz respeito ao tipo de participantes nestes mercados, à sua liquidez e à relação entre seus dois segmentos.

\footnotetext{
${ }^{5}$ Para Bresser-Pereira (2010 p.134): a doença holandesa "é produto de rendas ricardianas oriundas de abundantes recursos naturais que produzem uma taxa de câmbio (...) incompatível com a competitividade internacional dos setores de bens comercializáveis". Nesta perspectiva, a taxa de câmbio no Brasil teria se apreciado em função, sobretudo, dos fluxos comerciais gerados pelas exportações de commodities (canal direto).
} 
Outro aspecto relevante a ser destacado nas características do mercado de câmbio de economias emergentes está relacionado à internacionalização das suas moedas, que exerce influência na dinâmica cambial desses países por meio de três canais: (i) operações de carry-trade; (ii) crescimento dos respectivos mercados de câmbio em relação às trocas comerciais; (iii) participação do mercado de derivativos em relação ao mercado à vista.

A internacionalização monetária também exerce influência na dinâmica cambial das economias emergentes por meio das operações de carry-trade ${ }^{6}$. Como destacam He e McCauley (2012), suas moedas são demandadas como "moedas de investimento" nos mercados offshore devido às taxas de juros mais elevadas comparativamente aos países centrais. Assim, nos momentos de baixa preferência pela liquidez em âmbito internacional, essa "internacionalização assimétrica" gera pressões de apreciação nos mercados onshore associadas à arbitragem feita por instituições que operam nos dois mercados, exigindo intervenções mais frequentes das autoridades monetárias para conter a volatilidade cambial.

A principal especificidade do mercado cambial brasileiro reside na assimetria regulatória entre o segmento à vista e o de derivativos cambiais que torna este segundo mercado mais líquido do que o primeiro (Prates, 2015). Enquanto no mercado à vista apenas os bancos podem deter posição em moeda estrangeira, no mercado de derivativos todos os agentes estão autorizados a participar. Contudo, nesse último segmento a liquidação não pode ser realizada mediante entrega de moeda estrangeir. Assim, como destacado em diversos trabalhos, o mercado futuro de dólar é o lócus de formação da taxa de câmbio R \$/US\$ devido à sua maior liquidez. A taxa formada nesse mercado é transferida ao mercado à vista por meio de operações de arbitragem realizada pelos bancos (Ventura e Garcia, 2012; Rossi, 2016). Isto não ocorre no México, onde apesar de existirem algumas restrições para a abertura de contas em dólar, há uma maior variedade de agentes que podem participar em ambos os mercados. Como pode ser visto no Gráfico 2, a relação entre os contratos de derivativos e os contratos spot é maior no Brasil em todos os períodos.

\footnotetext{
${ }^{6}$ As estratégias de carry trade (ou derivative carry trade, quando realizadas nos mercados de derivativos), são transações que procuram lucrar com o diferencial de juros, financiando a posição em investimentos denominados em moedas com altas taxas de juros (investment currencies) com dívida denominada em moedas com baixas taxas de juros (funding currencies). Essas estratégias têm despertado a atenção das autoridades regulatórias, pois podem ameaçar estabilidade macroeconômica e financeira ao contribuir para períodos prolongados de apreciação cambial, seguidos de depreciações repentinas (BIS, 2015 p.1).
} 
No México, os menores controles sobre as transações cambiais tornaram seu mercado à vista mais líquido e permitiram uma internacionalização mais acelerada, sendo o peso mexicano utilizado inclusive como proxy para operações com outras moedas emergentes. Desde 2010, por exemplo, a moeda mexicana participa do World Government Bond Index. Como esse índice é utilizado como um benchmark por muitos investidores, isso pode ter elevado a demanda pela moeda e instrumentos financeiros mexicanos. Além disso, o peso mexicano é uma moeda atrativa para realizar hedge sobre exposições cambiais em outras moedas emergentes devido a sua maior liquidez de mercado e menor custo (taxa de juros).

A heterogeneidade do marco regulatório entre ambos os países também explica as diferenças entre os instrumentos negociados (onshore e offshore) e o tamanho relativo do mercado offshore. Enquanto no Brasil os contratos à termo sem entrega nesse mercado (os Non-Deliverable Forward - NDF) e o contrato futuro da BM\&FBovespa (onshore) são mais relevantes, no México os swaps, negociados em mercado de balcão, são mais relevantes (Gráfico 2).

Gráfico 3. Instrumentos negociados e relação entre os mercados de derivativos e à vista

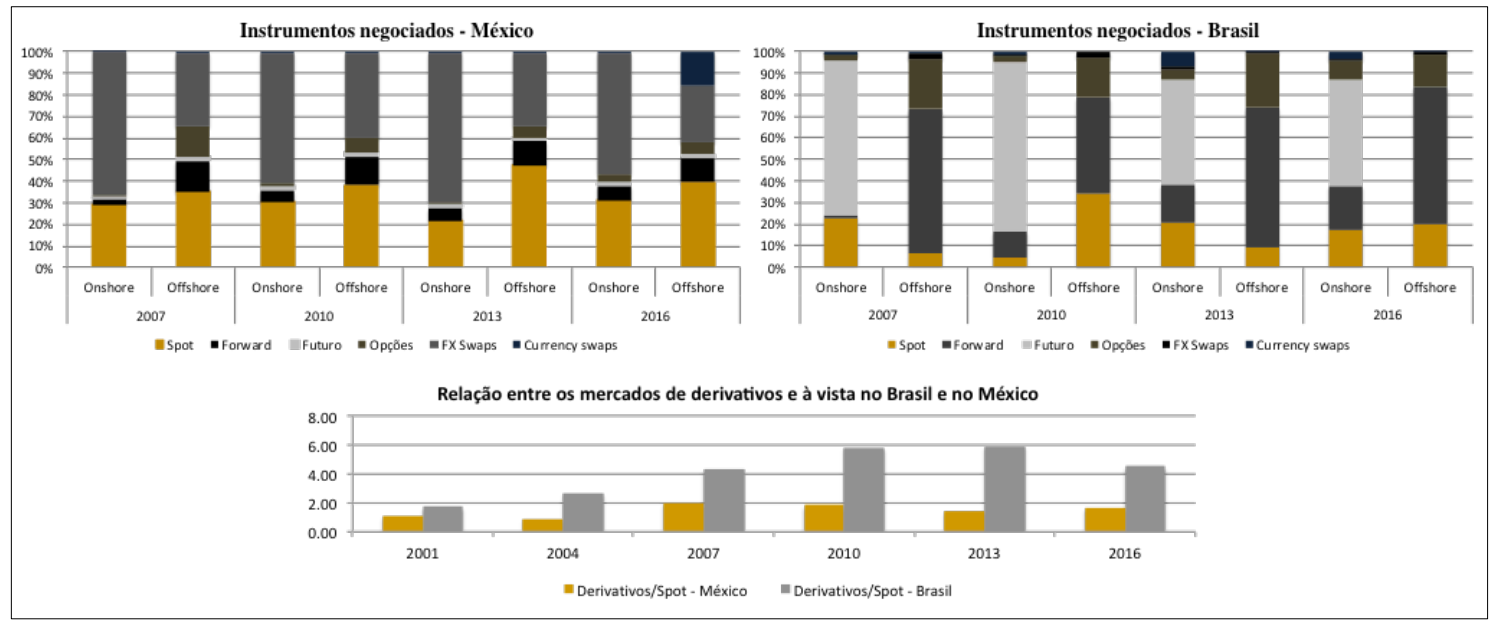

Fonte: BIS (2007,2010,2013,2016). Elaboração própria.

As menores restrições no terceiro nível de abertura também contribuem para a maior participação dos mercados offshore e de investidores não residentes nas negociações onshore com a moeda mexicana, se comparada com a moeda brasileira. Em 2016, o mercado offshore respondia por $80 \%$ das negociações no México e por $43 \%$ das negociações no Brasil. Em contrapartida, cerca de $68 \%$ das transações no México foram realizadas por investidores não residentes, enquanto no Brasil estes representam 52\% das negociações (Gráfico 3). 
Gráfico 4. Participação dos investires estrangeiros e do mercado offshore

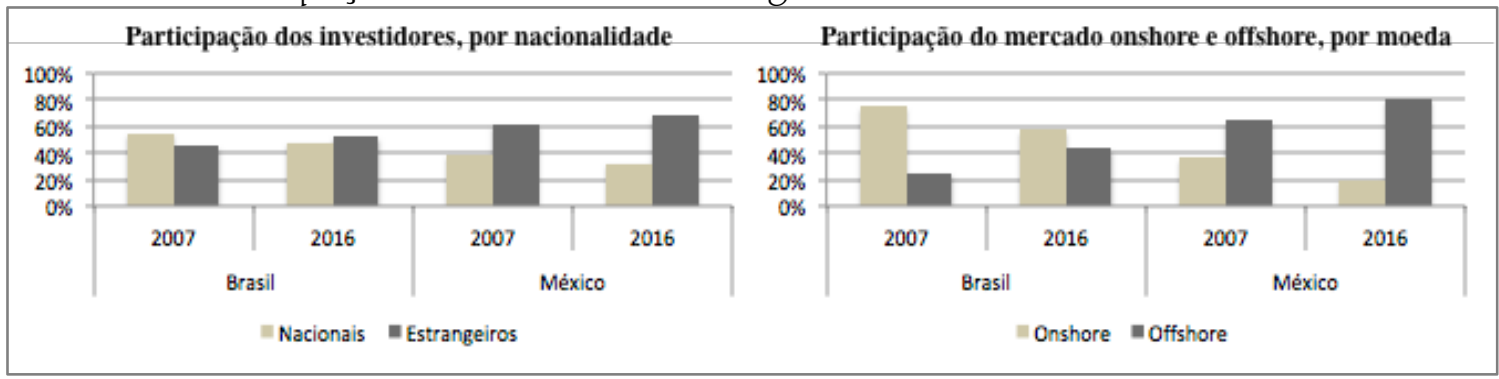

Fonte: BIS (2007,2010,2013,2016). Elaboração própria.

Assim, de modo geral, a moeda mexicana tem um giro (turnover) mais elevado que a moeda brasileira e apresenta um maior grau de internacionalização. Porém, a relação entre o tamanho do mercado de câmbio e as trocas comerciais no Brasil é, de modo geral, maior do que no México (Gráfico 4). Desse modo, se o mercado de câmbio mexicano pode ser considerado mais internacionalizado do que o brasileiro, devido à maior participação de investidores estrangeiros e das negociações no exterior, o indicador proposto por Ramos (2016), o mercado da moeda brasileira apresenta uma integração mais financeirizada ${ }^{7}$ do que a mexicana.

Gráfico 5. Tamanho do mercado de câmbio

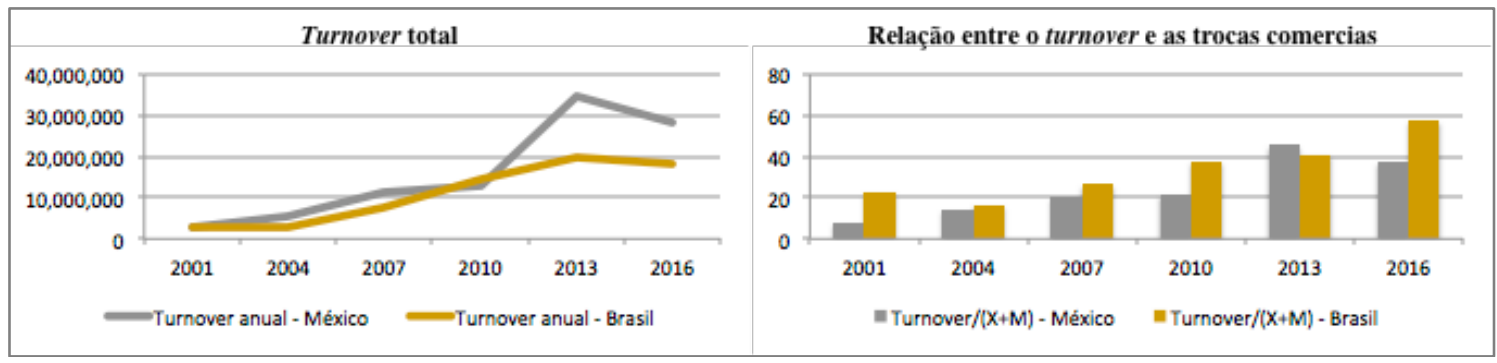

Fonte: BIS (2007,2010,2013,2016), IMF (2019). Elaboração própria

\subsection{Características do regime de câmbio flutuante}

Enquanto o regime cambial se refere à forma de determinação da taxa de câmbio, a política cambial consiste no modus operandi desse regime em relação aos seus objetivos. Estes, por sua vez, condicionam as metas e as estratégias de atuação da autoridade monetária no mercado cambial. Enquanto os objetivos da política estão relacionados a questões macroeconômicas, as metas estão relacionadas a variáveis mais específicas como, por exemplo, um determinado patamar da taxa de câmbio, quando o objetivo macroeconômico é a manutenção da competividade. Em contrapartida, as estratégias de atuação estão relacionadas

\footnotetext{
${ }^{7} \mathrm{O}$ indicador de integração financeirizada proposto por Ramos (2016) adiciona aos indicadores tradicionais de integração financeira o tamanho e sofisticação do mercado de câmbio.
} 
ao mercado onde serão realizadas as intervenções, assim como sua dimensão e os instrumentos utilizados (Prates, 2010).

Durante os anos 1980, o Brasil e o México conviveram com elevadas taxas de inflação, determinadas, em última instância, pela restrição externa (decorrente da crise da dívida externa), que gerou uma incerteza estrutural em relação à evolução da taxa de câmbio. Essas altas taxas de inflação foram combatidas com programas de estabilização com âncora cambial baseados em regimes de câmbio administrado. Contudo, esses regimes, viabilizados pelo retorno dos fluxos de capitais voluntários no início dos anos 1990, foram acusados de terem resultado em sobreapreciação cambial nas suas fases iniciais e de serem vulneráveis a ataques especulativos, que culminaram em crises cambiais. Assim, após as respectivas crises financeiras, ambos os países migraram para um regime de câmbio flutuante e, posteriormente, para um regime de metas de inflação. A combinação desses regimes tem levado alguns autores a levantar a hipótese de uma implícita subordinação da política cambial à política monetária, cujo principal objetivo é a estabilidade de preços tanto no Brasil (Prates, 2010; Serrano, 2010) como no México (Ros, 2015; Carrasco e Ferreiro, 2013). Nesta perspectiva, isto teria contribuído para uma apreciação cambial nesses países. Porém, como uma política de moeda apreciada contradiz a estratégia mexicana de crescimento liderado pelas exportações, Capraro (2015) argumenta que os baixos salários no México têm funcionado como forma de compensar a perda de competividade externa, uma vez que eles têm um efeito oposto ao da apreciação sobre o patamar da taxa de câmbio efetiva.

As metas de ambos os regimes também foram similares e variaram em função da conjuntura externa (comum) e interna (específica). Porém, estes possuem algumas diferenças no seu formato institucional e estratégias de intervenção (Tabela 2). 
Tabela 2. Características do Regime de Cambio Flutuante

\begin{tabular}{|c|c|c|c|}
\hline & & Brasil & México \\
\hline \multirow{4}{*}{$\begin{array}{c}\text { Formato Institucional do } \\
\text { Regime }\end{array}$} & $\begin{array}{l}\text { Decisões sobre a escolha do } \\
\text { regime e seus objetivos }\end{array}$ & Banco Central & $\begin{array}{c}\text { Comissão de Câmbio } \\
\text { (Governo e Banco Central) }\end{array}$ \\
\hline & Operador da política cambial & Banco Central & Banco Central \\
\hline & $\begin{array}{c}\text { Decisões sobre a condução da } \\
\text { política cambial }\end{array}$ & Banco Central & $\begin{array}{c}\text { Comissão de Câmbio } \\
\text { (Governo e Banco Central) }\end{array}$ \\
\hline & Propriedade das Reservas & Tesouro & Banco Central \\
\hline & Mercado de operação & À vista e derivativos & À vista e derivativos \\
\hline Estratégia & Instrumentos utilizados & $\begin{array}{l}\text { Mercado de derivativos: Swaps } \\
\text { Mercado à vista: Compra e venda no } \\
\text { mercado à vista, linhas de recompra, } \\
\text { empréstimos ocasionais em moeda } \\
\text { estrangeira }\end{array}$ & $\begin{array}{l}\text { Mercado de derivativos: Opções } \\
\text { Mercado à vista: Compra e venda no } \\
\text { mercado à vista, linhas de recompra, } \\
\text { empréstimos ocasionais em moeda } \\
\text { estrangeira e intervenção indireta } \\
\text { (operações com PEMEX e Governo } \\
\text { Federal) }\end{array}$ \\
\hline \multicolumn{2}{|c|}{ Objetivo explícito do Regime } & $\begin{array}{l}\text { Não há menção explícita sobre os objetivos } \\
\text { macroeconômicos da polítca cambial }\end{array}$ & $\begin{array}{l}\text { Não há menção explícita sobre os } \\
\text { objetivos macroeconômicos da política } \\
\text { cambial }\end{array}$ \\
\hline \multicolumn{2}{|c|}{ Metas do regime } & $\begin{array}{c}\text { Resistir a movimentos abruptos do patamar } \\
\text { da taxa de câmbio } \\
\text { Redução da volatilidade } \\
\text { Acúmulo de reservas } \\
\text { Manter liquidez no mercado de câmbio }\end{array}$ & $\begin{array}{l}\text { Resistir a movimentos abruptos do } \\
\text { patamar da taxa de câmbio } \\
\text { Redução da volatilidade } \\
\text { Acúmulo de reservas } \\
\text { Manter liquidez no mercado de câmbio }\end{array}$ \\
\hline \multicolumn{2}{|c|}{ Objetivo prioritário do Banco Central } & Controle de preços & Controle de preços \\
\hline
\end{tabular}

Fonte: BCB (2019), BM (2019). Elaboração própria.

Enquanto no Brasil as decisões de política cambial são tomadas pelo BCB, no México esta decisão é compartilhada entre o Banco Central do México (BCM) e o governo federal (Ministério da Fazenda). Porém, na prática, esta diferença não gerou divergência entre os objetivos perseguidos uma vez que não houve conflitos entre as escolhas do governo e do BCM (Ros, 2015).

A diferença em relação às estratégias de intervenção é mais evidente. No Brasil, a acumulação de reservas é feita, essencialmente, por meio de compras pelo $\mathrm{BCB}$ de moeda estrangeira no mercado à vista. Estas são administradas pelo BCB, mas pertencem formalmente ao Tesouro Nacional. Assim, os ganhos ou perdas associados à administração das reservas pelo BCB são convertidos em receitas ou despesas da União (Prates, 2010). Já para conter a volatilidade cambial, o BCB tem atuado, com mais intensidade desde 2002, no mercado de derivativos por meio de leilões de contratos de swaps. No Gráfico 5, são apresentadas as intervenções no mercado à vista e de derivativos, sendo que o sinal dos swaps foi ajustado para que todos os valores negativos indiquem venda de dólares. 
Gráfico 6. Intervenções no mercado de câmbio brasileiro, em US\$ milhões

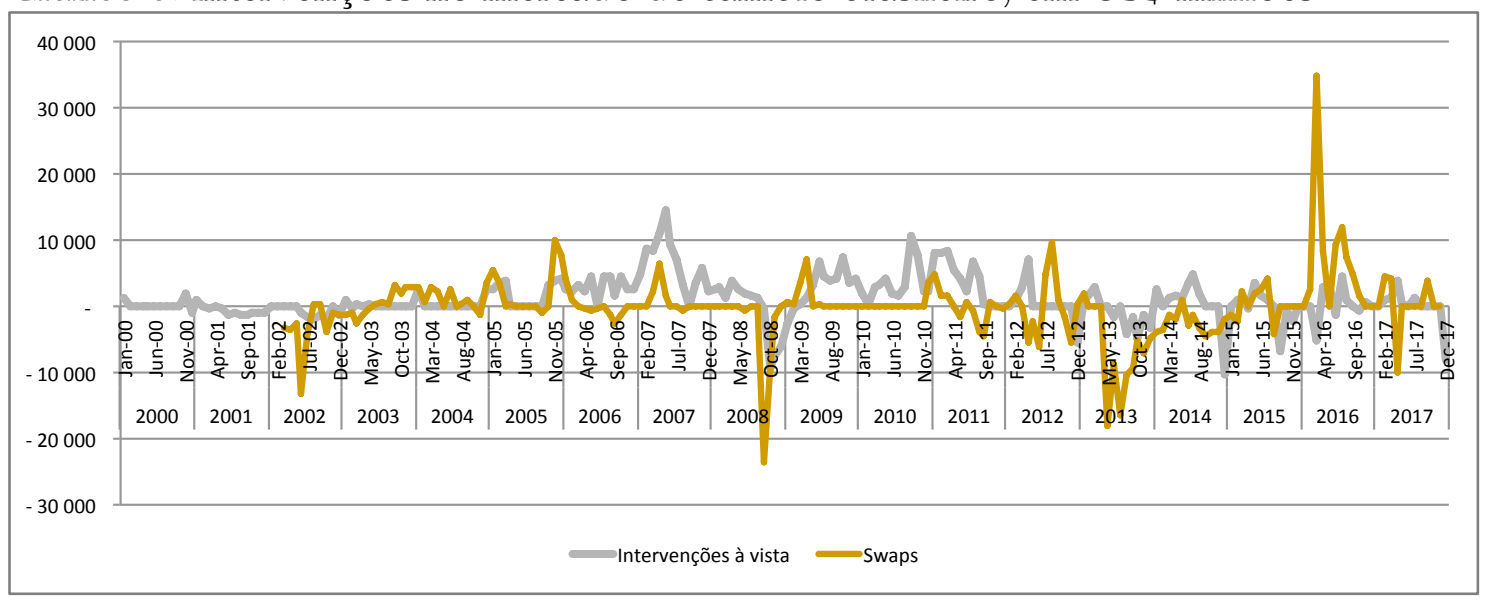

Fonte: BCB (2019). Elaboração própria.

Já no México a acumulação de reservas foi realizada, sobretudo, por meio de instrumentos de derivativos, com leilões de opções de venda de caráter deliverable. Esses leilões, contudo, complementaram a acumulação mais estrutural da intervenção indireta, que é feita por meio da obrigatoriedade da Pemex e do Tesouro realizarem suas operações cambiais com o BCM (Sidaoui, 2005; Ros, 2015). Como o fluxo de moeda externa entre 1995 até 2016 recebido pela Pemex foi maior do que as necessidades do governo federal para pagar o serviço da dívida externa, esta tem sido a principal fonte de acumulação de reservas internacionais mexicanas.

Os dados disponíveis sobre as intervenções do BCM no mercado de câmbio (Gráfico 6) apontam que a intensidade das intervenções é maior no México do que no Brasil.

Gráfico 7. Intervenções no mercado de câmbio mexicano, em US\$ milhões

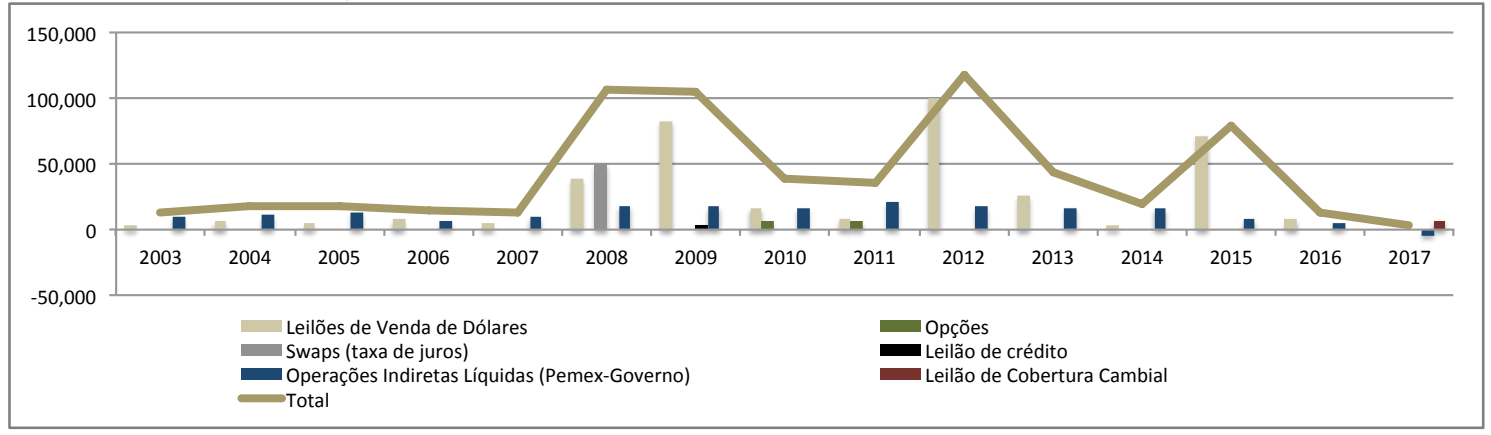

Fonte: BM (2019). Elaboração própria. 


\subsection{Dinâmica das taxas de câmbio}

Ao longo do período analisado, as taxas de câmbio de ambos os países apresentaram um padrão cíclico, formado por tendências de curto e médio prazo de apreciação e depreciação cambial. Como pode ser observado no Gráfico 7, entre janeiro de 2000 e junho de 2008, a taxa de câmbio mexicana seguiu uma trajetória relativamente estável em comparação à brasileira. Neste período, a moeda brasileira apresentou um comportamento cíclico, com forte tendência à depreciação (Jan/2000 a Dez/2002) e posterior apreciação (Jan/2003 a Jun/2008). Porém, após esse período, as taxas de câmbio analisadas mostraram movimentos e tendências mais similares.

Gráfico 8. Trajetória das taxas de câmbio, em número índice

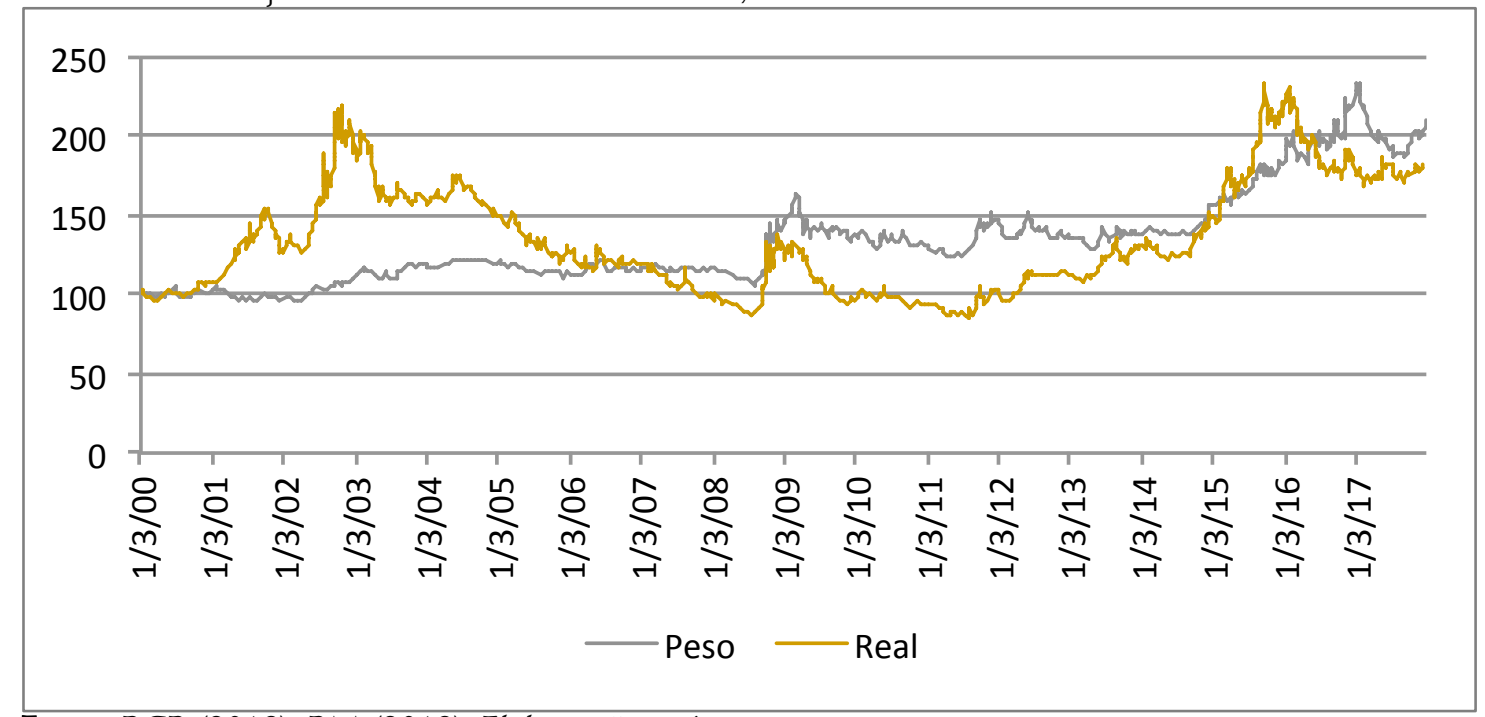

Fonte: BCB (2019), BM (2019). Elaboração própria.

Considerando como medida de volatilidade a frequência das variações extremas, aqui definidas como variações diárias maiores do que 3\%, a taxa de câmbio brasileira apresentou um comportamento mais volátil em relação à mexicana ${ }^{8}$, independente da direção. Porém, apesar de ambas as taxas terem alcançado depreciações maiores do que $6 \%$, apenas o real alçou apreciações similares (Gráfico 8).

\footnotetext{
${ }^{8}$ Esta medida é preferível pois permite traçar um indicativo do número de vezes em que as variações se mostraram elevadas e da sua direção (Ramos, 2016). Contudo, mesmo utilizando outras medidas de volatilidade as conclusões não se alteram.
} 
Gráfico 9. Frequência das variações extremas (2000 - 2017)

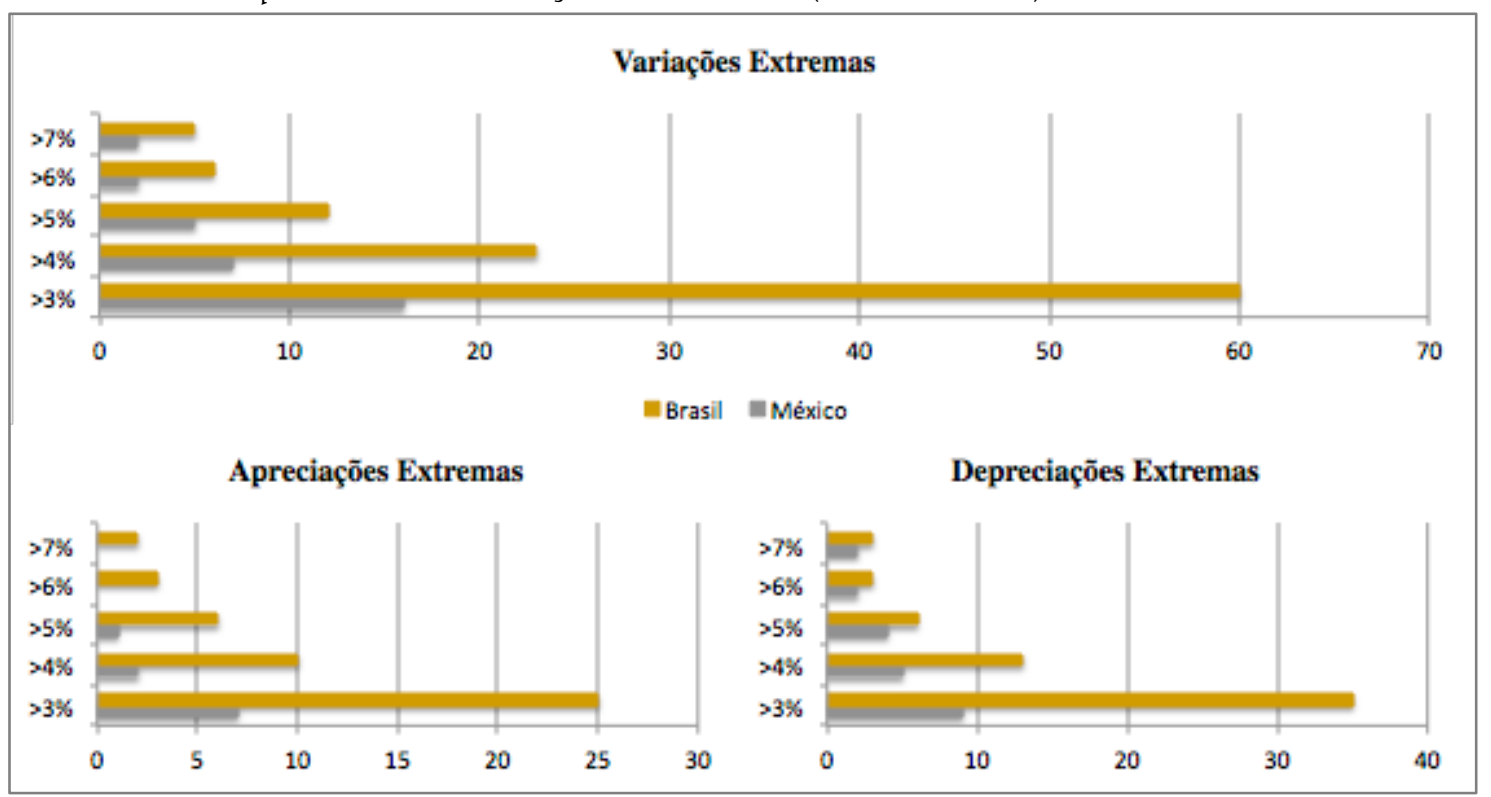

Fonte: BCB (2019), BM (2019). Elaboração própria.

\subsection{Determinantes da dinâmica cambial}

Para uma aproximação das correlações entre os determinantes da dinâmica cambial e as variações na taxa de câmbio durante o período analisado, foi realizado o cálculo das correlações das séries por meio do coeficiente de correlação de Pearson. Como o intervalo analisado esteve marcado por um ambiente internacional conturbado, ao invés considerar a média do período completo, optouse por dividir o período analisado em subperíodos 9 , cuja delimitação foi determinada pelas fases dos ciclos de fluxos de capitais para as economias emergentes (Gráfico 9).

Na fase 1 (Jan/2000 - Dez/2002), de baixa do ciclo dos anos 1990, ambos os países haviam adotado o regime de flutuação cambial e possuíam uma ampla abertura financeira. A fase 2 (Jan/2003 - Jun/2007) inicia-se com o aumento dos fluxos de capitais para as economias emergentes num contexto de abundância de liquidez internacional e alta dos preços das commodities. Os dois booms perdem impulso com a crise do segmento subprime do mercado imobiliário americano em meados de 2007, se revertendo com o seu agravamento no primeiro semestre de 2008 (Prates, 2015). A eclosão dessa crise marca o início da fase 3 (Jul/2007Dez/2008), se estendendo até o período mais agudo da crise financeira internacional, que eclodiu em setembro de $2008 \mathrm{com}$ a quebra do banco Lehman Brothers e acentuou a fuga de capitais das economias emergentes. Com o rápido 
retorno desses fluxos para essas economias já no início de 2009, estimulado pelas taxas de juros baixas nos países centrais e pela política de quantitative easing americana, emerge a fase 4 (Jan/2009 - Dez/2010), caracterizada por um novo período de alta liquidez internacional. Em 2011 inicia-se a fase 5, período marcado por algumas turbulências no mercado internacional como a crise da área do euro, que se estende até abril/2013. Já a fase 6, se inicia em maio de 2013, com a sinalização pelo então presidente do Federal Reserve, Ben Bernanke, de que a desmontagem da política de quantitative easing se iniciaria ainda em 2013 (tapering talk), se estendendo até o final do período analisado. Como pode ser observado no gráfico 11, com exceção da fase 2, o co-movimento entre ambas as taxas é elevado (coeficiente acima de 0,4) em todas as fases analisadas, corroborando a análise gráfica da subseção anterior.

Gráfico 10. Fluxos de capitais para os países emergentes

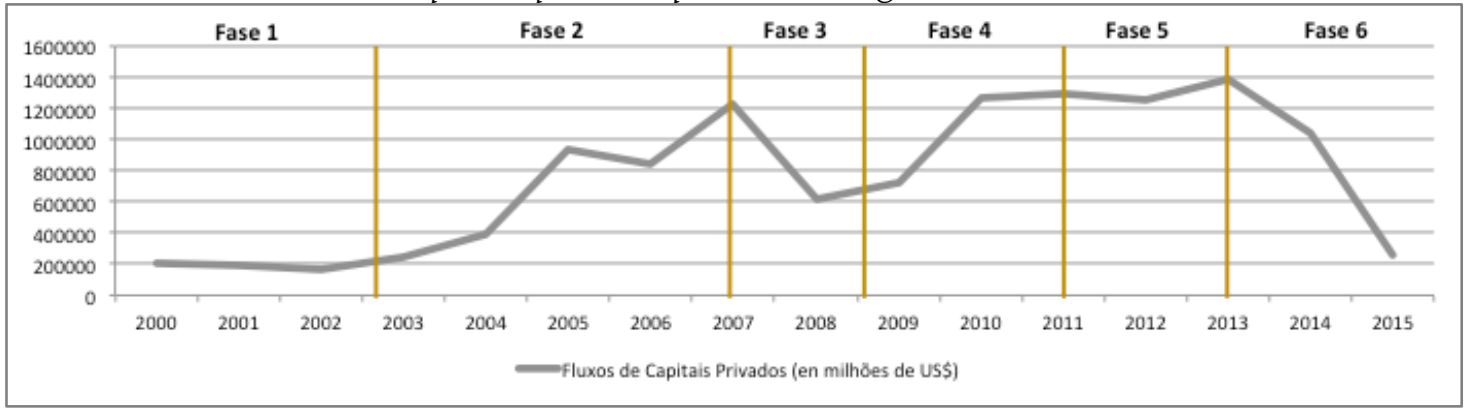

Fonte: IIF (2019). Elaboração própria.

Adicionalmente, para uma aproximação da dinâmica de curto prazo das correlações durante o período analisado, também foi realizado o cálculo da correlação das variações das séries por meio do método EWMA (Exponentially Weighted Moving Average), que permite a análise da dinâmica da correlação sem a necessidade de predeterminar uma janela de tempo.

Este método, popularizado pela RiskMetrics ${ }^{\mathrm{TM}}$, é utilizado pela sua simplicidade e por produzir resultados similares aos de modelos mais sofisticados tanto para estimativas de volatilidade como de correlação (Brooks e Chong, 2001, Ferreira e Lopez, 2005; Coudert e Gex, 2010). Nesta metodologia, a média móvel é calculada ponderando os componentes por um fator exponencial, de modo que valores recentes passam a ter maior importância. Definindo $r_{x, t}$ e $r_{y, t}$ como o retorno da série $x$ e $y$, respectivamente, o desvio padrão $(\sigma)$ de cada série pode ser calculado da forma autoregressiva conforme a equação 5 e a estimativa da correlação $(\rho)$ entre elas conforme a Equação 6, onde o parâmetro $\lambda$, que varia 
entre 0 e 1 , é o fator de declínio e quanto maior o seu valor maior é o peso dado às observações recentes.

$$
\begin{aligned}
& \sigma_{x, t} \approx \sqrt{(1-\lambda) r_{x, t-1}^{2}+\lambda \sigma_{t-1}^{2}} \\
& \rho_{x y, t} \approx(1-\lambda) \frac{r_{x, t-1} r_{y, t-1}}{\sigma_{x, t-1} \sigma_{y, t-1}}+\lambda \rho_{x y, t-1}
\end{aligned}
$$

Uma fragilidade da metodologia reside na escolha do valor do parâmetro $\lambda$. Como não há um método ótimo para seu cálculo, neste trabalho o $\lambda$ foi considerado igual a 0,94 (valor proposto pela RiskMetrics ${ }^{\mathrm{TM}}$ para diversos mercados) para as variáveis diárias e semanais e de 0,97 para mensais ${ }^{10}$.

Como mostra o Gráfico 10, as correlações entre os movimentos das moedas possuem uma ampla variação ao longo dos períodos analisados. Além disso, observa-se um aumento no patamar desta correlação a partir da metade da fase 2 (que é captado pela elevação do coeficiente de Pearson na fase 3) e uma queda do co-movimento das duas moedas durante o final da fase 5 , medido pelo método EWMA.

Gráfico 11. Correlação entre as taxas de câmbio

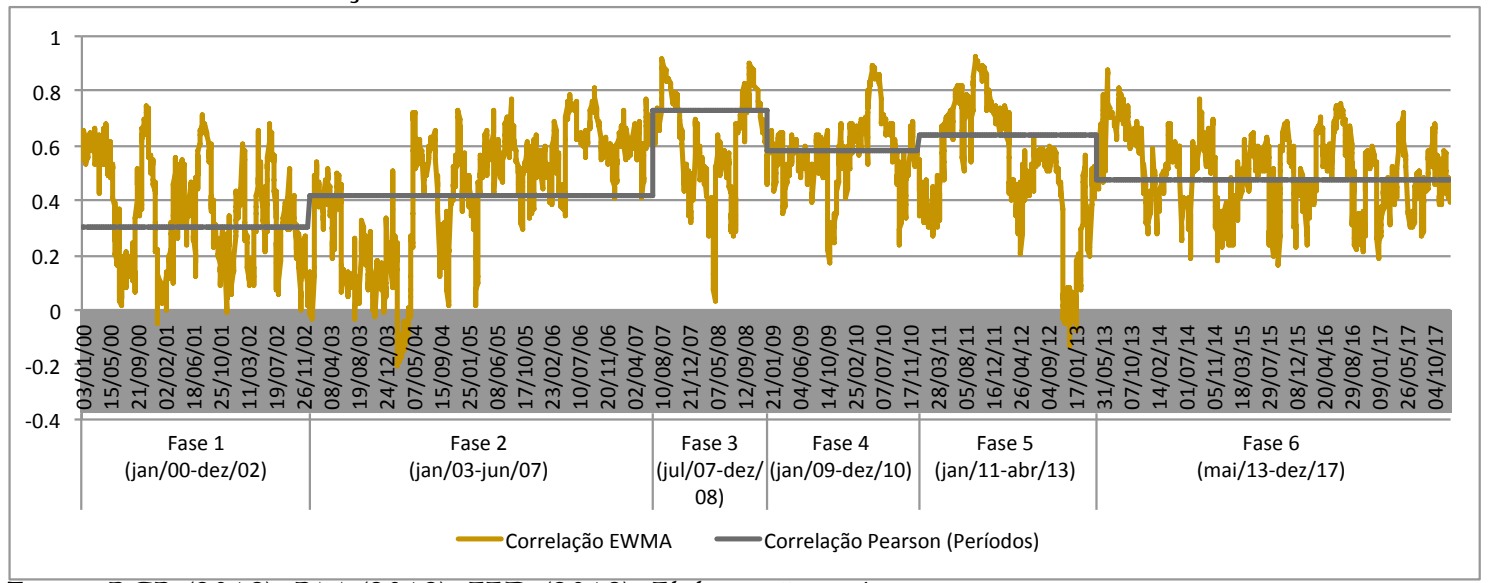

Fonte: BCB (2019), BM (2019), FED (2019). Elaboração própria.

\subsection{Preferência pela liquidez internacional}

Um fator essencial para entender a dinâmica cambial das moedas emitidas por economias periféricas é o seu menor prêmio de liquidez em relação às moedas centrais em geral e, em especial, à divisa-chave. Esta diferença de liquidez das moedas $\left(l^{*}-l\right)$ é uma variável estrutural de difícil mensuração, contudo,

\footnotetext{
${ }^{10} \mathrm{~A}$ análise por meio deste método não foi realizada para variáveis com frequência trimestral devido à ausência de referencial para $\circ \lambda$.
} 
assumindo que os países analisados possuem uma posição similar na hierarquia monetária internacional este diferencial foi assumido como constante e igual a 1. Desse modo a análise se concentra no peso $(\beta)$ dado ao prêmio de liquidez.

Nesta seção, esta preferência pela liquidez foi aproximada pela percepção de risco sobre cada economia em particular utilizando dados do mercado de swaps cambiais de crédito (Credit Default Swaps - CDS).

Os CDS soberanos são medidos em pontos base e, quanto mais elevados, maior é a percepção de risco de crédito do país. Ou seja, a percepção da capacidade do país de honrar seus compromissos financeiros externos é menor. Assim, a piora na percepção da qualidade de pagamento do país pode levar à saída de capitais e reversão nas posições nos mercados de derivativos cambiais (de vendida para comprada em dólar) gerando impacto nas taxas de câmbio. Como apresentado no Gráfico 11, momentos de queda (elevação) no risco soberano são geralmente acompanhados de movimentos de apreciação (depreciação) nas taxas de câmbio.

Gráfico 12. Correlação entre os CDS e as taxas de câmbio

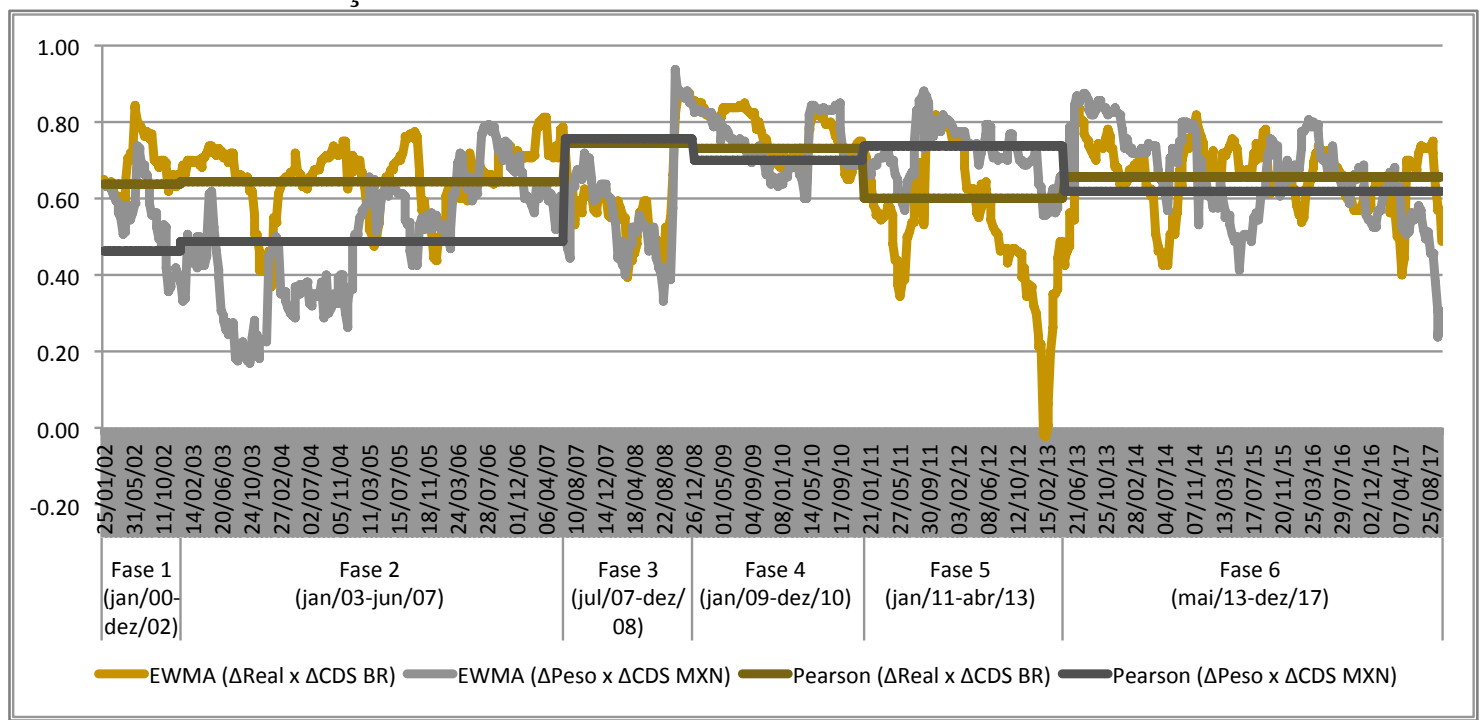

Fonte: BCB (2019), BM (2019); Bloomberg (2019). Elaboração própria

Ao longo de grande parte do período analisado, as variações das duas moedas apresentaram uma correlação elevada e similar com o respectivo CDS, porém com diferenças mais acentuadas em alguns períodos das fases 2 e 5 . Na fase 2 , a correlação entre as variações da moeda mexicana é menor do que a brasileira, mantendo níveis baixos quando comparados com o período total. Já durante a fase 5 esta correlação entre o CDS e o real foi menor, apresentando uma queda entre o final de 2011 e final de 2012, com posterior elevação. 
No caso do Brasil, este resultado pode ser explicado pela imposição de IOF sobre investimentos de portfólio no país e captações externas e sobre o excesso de posições vendidas em derivativos cambiais, que contribuiu para deter o processo de apreciação cambial (Prates, 2015). Já no caso mexicano, uma hipótese é a ocorrência de um deslocamento da demanda para outras moedas emergentes. Como a fase 2 compreende um período de alta liquidez internacional e de elevação no preço das commodities, as expectativas de apreciação cambial em economias exportadoras de produtos primários que, além disso, possuem um maior diferencial de juros do que a moeda mexicana, podem ter gerado maiores expectativas de retorno total para os investidores internacionais.

Todavia, apesar da percepção de risco dos investimentos no Brasil ter sido mais elevada do que no México na maior parte do período, a diferença entre a volatilidade de ambos os países não foi muito significativa (Gráfico 12).

Gráfico 13. Volatilidade dos CDS

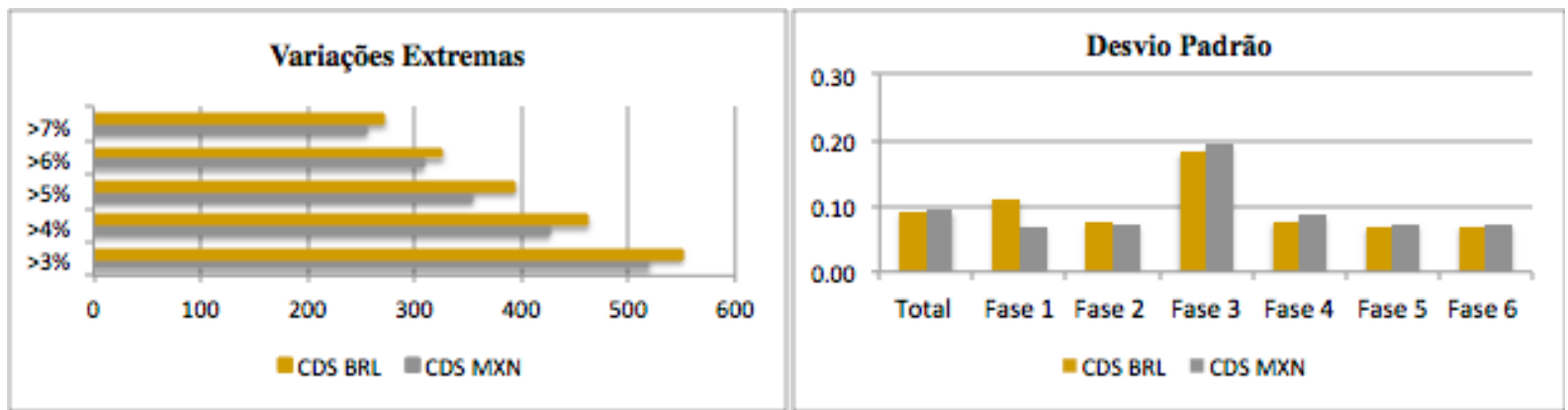

Fonte: Bloomberg (2019). Elaboração própria

\subsection{Diferencial de Juros}

O diferencial de juros foi calculado utilizando as taxas de juros dos mercados interbancários dos respectivos países ${ }^{11}$. $\bigcirc$ Gráfico 13 apresenta a evolução do diferencial de juros, em módulo. No México, o diferencial de juros apresentou uma média de $5 \%$ ao longo do período analisado, com diferencial máximo de cerca de $14 \%$ e mínimo de $2 \%$. Já no Brasil, a média desse diferencial no período foi de $12 \%$, tendo atingido o valor máximo de quase $25 \%$ e mínimo de cerca de $5 \%$.

\footnotetext{
${ }^{11}$ As taxas utilizadas foram a taxa CDI no caso do Brasil, a taxa "Fondeo Bancario" do México e a TBill de 3 meses para os Estados Unidos.
} 
Gráfico 14. Diferencial de juros

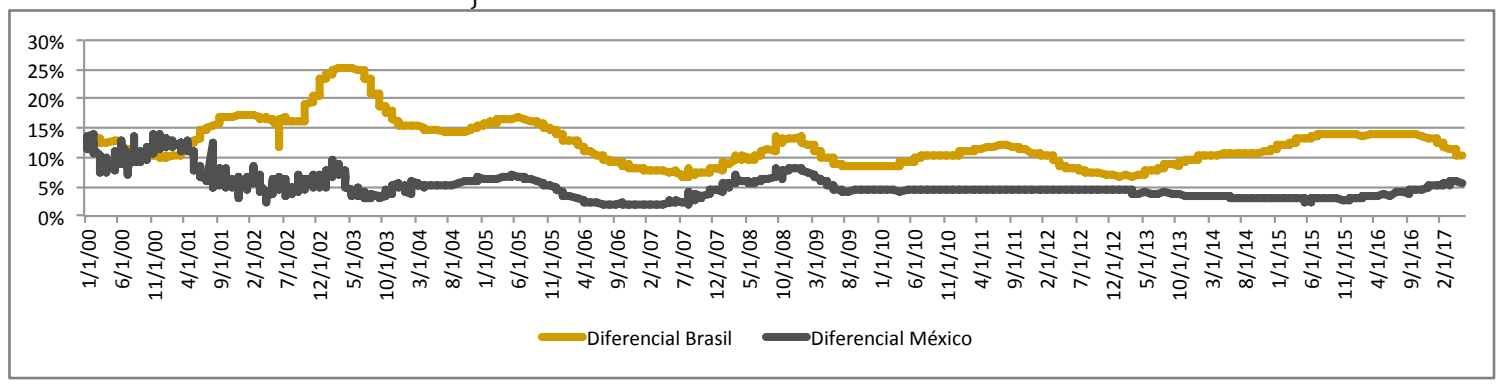

Fonte: BCB (2019), BM (2019), FED (2019). Elaboração própria.

No Gráfico 14, a correlação negativa com as moedas indica que aumentos no diferencial de retorno estão associados movimentos de apreciação cambial. Este foi o caso do Brasil na maior parte das fases 1, 2 e 5, como mostram os resultados da correlação de Pearson por período. Já no México, esta correlação só foi negativa durante a fase 6. Porém, os resultados da correlação entre estas variáveis pelo método EWMA indicam uma dinâmica com amplas variações ao longo de todo o período. Este resultado aponta para a necessidade de um melhor estudo da relação entre as taxas de juros e de câmbio.

Gráfico 15. Correlação entre o diferencial de juros e a taxa de câmbio

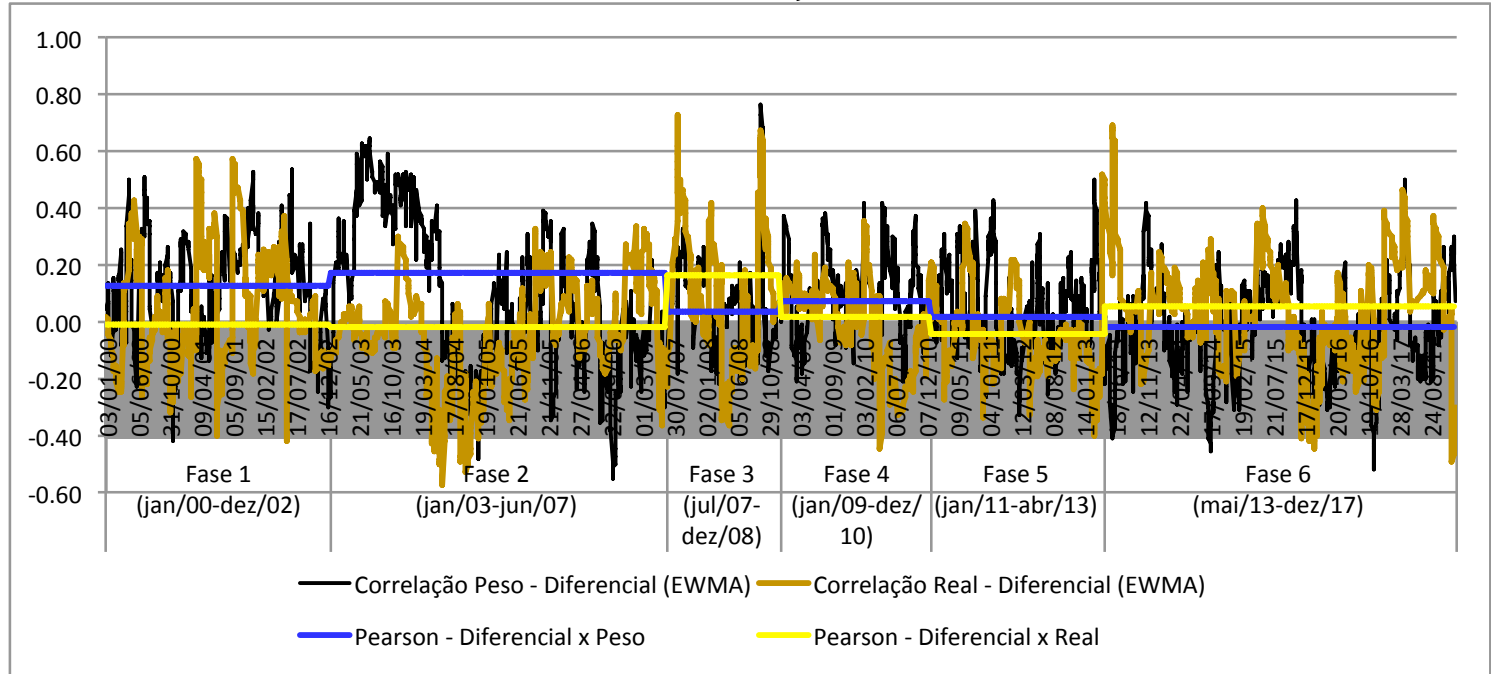

Fonte: BCB (2019), BM (2019), FED (2019). Elaboração

Em contrapartida, a volatilidade desse diferencial, medida pela frequência das variações e pelo desvio-padrão, é maior no caso mexicano, mesmo desconsiderando os períodos em que taxa de juros do interbancário não era a meta da política monetária, como mostra o Gráfico 15. 
Gráfico 16. Volatilidade das taxas de juros

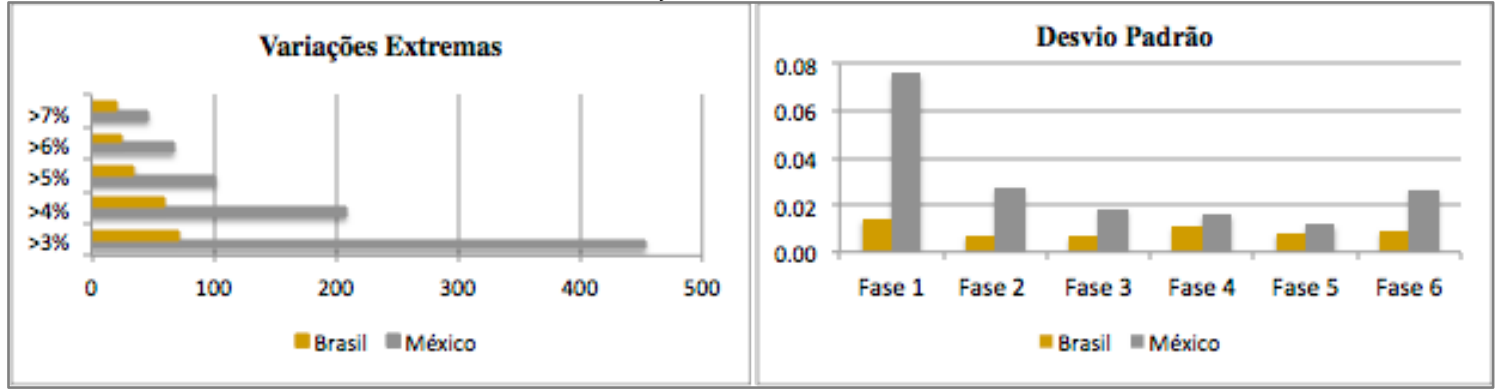

Fonte: BCB (2019), BM (2019), FED (2019). Elaboração própria.

Assim, a principal diferença entre o diferencial de juros dos dois países reside no patamar mais elevado da taxa de juros no caso brasileiro. Esse patamar estimula as operações de carry trade, principalmente via derivativos dada a institucionalidade do mercado de câmbio do Brasil. O fato destas operações serem mais atrativas no caso brasileiro pode justificar a maior relação entre o aumento do diferencial e apreciação do real.

Na perspectiva pós-keynesiana, são os fluxos financeiros e as posições nos mercados de derivativos cambiais que transmitem as variações nas expectativas sobre as taxas de câmbio futuras para a taxa de câmbio efetiva. Assim, as próximas duas subseções analisam a correlação desses canais com as taxas de câmbio. Ademais, como a proporção de produtos primários na pauta exportadora brasileira é significativa e a constituição de reservas internacionais da economia mexicana é altamente dependente das receitas de petróleo, a última subseção estuda a relação entre o preço dos commodities com as respectivas moedas.

\subsection{Características dos canais de transmissão: correlação com os fluxos financeiros}

Dada a relevância de fatores externos e das posições dos investidores estrangeiros em ativos das economias emergentes, nesta seção analisa-se os fluxos brutos de entrada de não residentes (Gráfico 16).

No Brasil, esses fluxos financeiros apresentaram uma associação linear negativa em todo o período analisado, de modo que entradas positivas de não residentes estão associadas a momentos de apreciação cambial. No México, esta correlação se torna negativa a partir da fase 2 com posterior elevação no período de crise, voltando a ser positiva durante as fases 5 e 6 . Por outro lado, há no Brasil, de modo geral, uma maior associação linear entre estes fluxos e as taxas de câmbio. 
Gráfico 17. Correlação entre as entradas brutas de não residentes e as taxas de câmbio

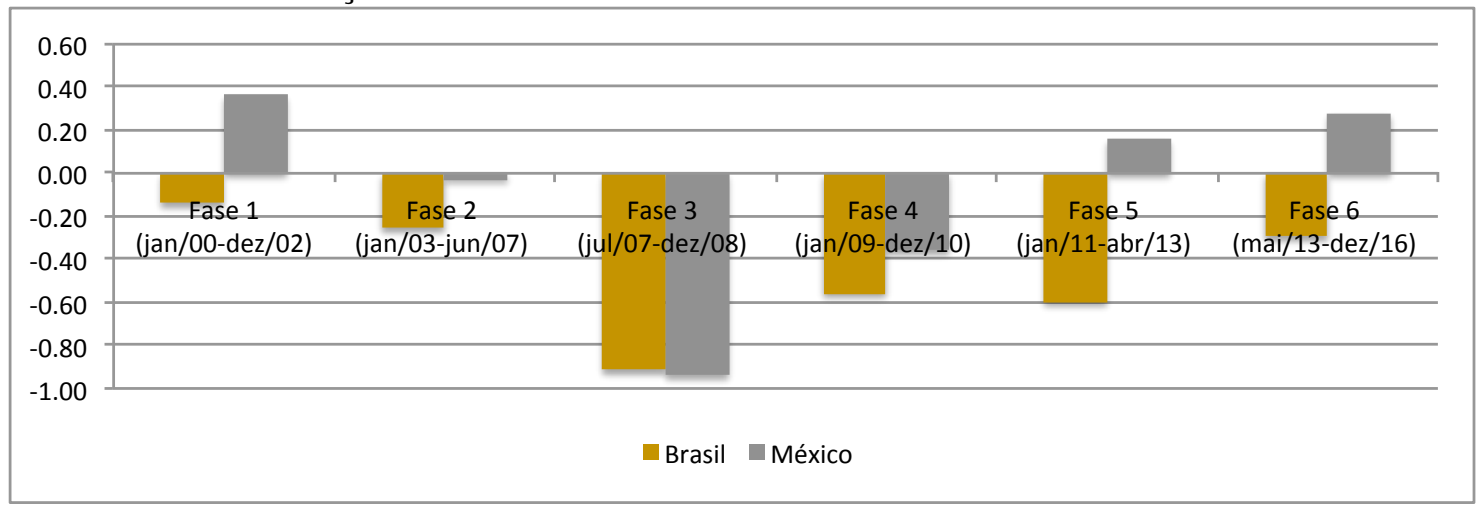

Fonte: BCB (2019), BM (2019), IMF (2019). Elaboração própria

Enquanto no Brasil os influxos de não residentes e as saídas brutas de capitais possuem uma volatilidade, medida pelo coeficiente de variação, relativamente similar, no México as saídas de residentes possuem uma maior volatilidade do que as entradas (Gráfico 17). Isto pode estar relacionado ao diferencial de juros entre os países. Como a rentabilidade no Brasil é mais elevada, as turbulências externas necessárias para abrir mão deste retorno (provocando saídas de capitais) devem ser maiores do que no caso mexicano, onde a rentabilidade é menor. Em contrapartida, dado a menor regulação sobre a moeda mexicana, as saídas de capitais também são facilitadas. Desse modo, se o México está mais vulnerável às saídas mais frequentes de capitais, estas podem ser mais intensas no Brasil, provocando depreciações mais bruscas, dado o maior volume que o diferencial de juros pode atrair.

Gráfico 18. Volatilidade dos fluxos totais brutos de entrada e saída (2000-2017)

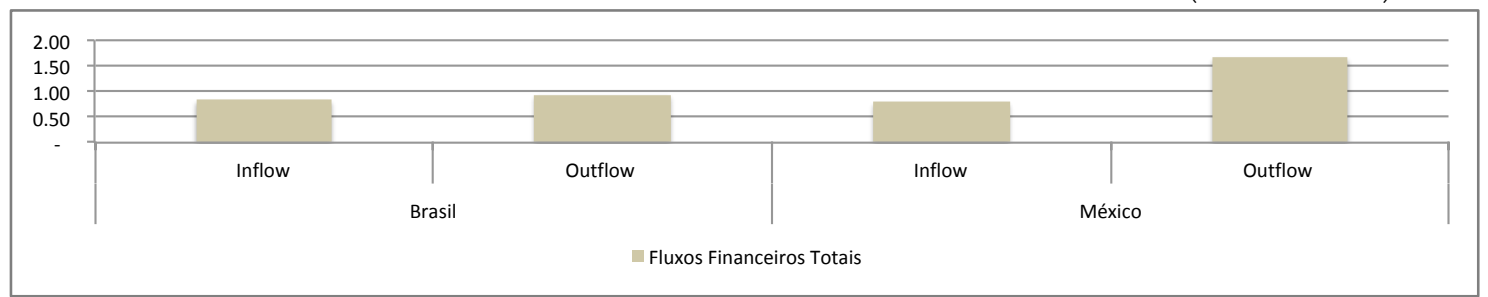

Fonte: IMF (2019). Elaboração própria.

\subsection{Características dos canais de transmissão: posições nos mercados de derivativos}

Outra característica que ajuda a explicar a dinâmica cambial é o tamanho e sofisticação do seu mercado cambial (Ramos, 2016). Ao apresentar maiores oportunidades para alavancagem, esses mercados tendem a concentrar volumes maiores de operações que podem gerar mudanças no mercado à vista de câmbio, sem que ocorram fluxos de capitais efetivos (Rossi, 2016). 
Apesar da relevância que esses instrumentos têm para a dinâmica cambial, não há dados com frequência diária ou mesmo mensal da maior parte das operações. Grande parte desses instrumentos são negociados em mercados de balcão, cujos dados são divulgados apenas em relatórios trienais do Bank for International Settlement (BIS). Porém, algumas estimativas da associação linear entre as taxas de câmbio e as posições de alguns agentes nos mercados de derivativos de bolsa podem ser realizadas.

No caso mexicano, algumas informações sobre os instrumentos de derivativos cambiais negociados em bolsa podem ser encontradas no site da U.S. Commodity Futures Trading Comission, que disponibiliza dados das negociações de futuros de peso mexicano na Chicago Mercantile Exchange (CME). Neste mercado os participantes estão divididos em três grupos: i) comerciais, quando a operação é realizada para fins de hedge; ii) não comerciais, relacionado a transações mais especulativas e iii) não reportáveis, para operações pequenas e não classificadas. $\bigcirc$ Gráfico 18 apresenta e os coeficientes de correlação destas posições com as variações da taxa de câmbio, sendo que valores negativos indicam que posição compradas (apostas na valorização do peso) estão associados a uma apreciação cambial. Este é o caso na maior parte do período das posições especulativas, de modo que esses agentes tendem a estar "do lado certo" das apostas neste mercado.

Gráfico 19. Coeficientes de correlação no mercado futuro de peso

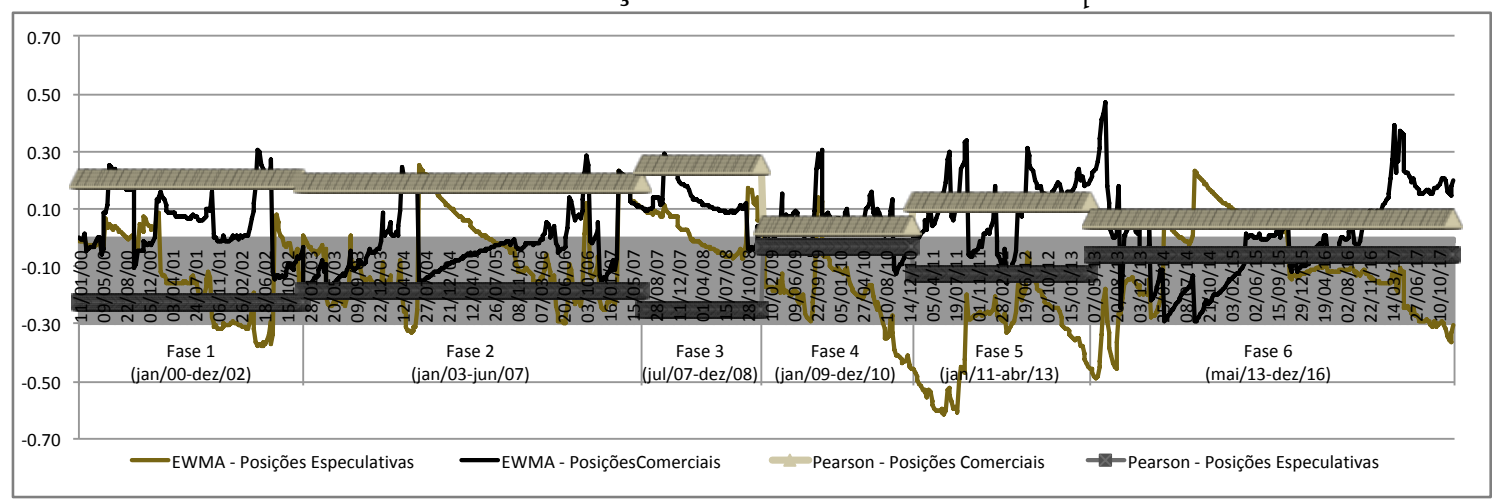

Fonte: BM (2019), CME Group (2019). Elaboração própria.

No Brasil, o mercado onshore é, ao contrário do México, mais líquido de modo que análise foi realizada pelas posições dos agentes no mercado futuro de dólar disponibilizadas pela bolsa brasileira (BM\&F). O Gráfico 19 apresenta o coeficiente de correlação das mudanças na posição dos principais agentes nesse mercado, com as variações na taxa de câmbio. Porém, diferentemente do caso anterior, como o objeto de negociação é a moeda estrangeira no Brasil, uma 
correlação negativa indica que variações positivas nesta posição (aposta na valorização do real) estão associadas a movimentos de apreciação cambial.

Na maior parte do período em análise, períodos de apreciação cambial estão associados a posições vendidas em dólares por investidores estrangeiros e institucionais, enquanto os bancos realizam a contraparte destas operações no mercado futuro. Para Rossi (2016, p.124) isto sinaliza que no Brasil enquanto os investidores estrangeiros e institucionais formam ou atenuam tendências, buscando ganhos especulativos, as instituições financeiras atuam como contraparte, obtendo ganhos de arbitragem ao transmitir a pressão (de apreciação ou depreciação) do mercado futuro para o mercado à vista. Isto não quer dizer que os bancos não realizem operações especulativas, ou que sua atuação se restrinja à atuação de contraparte passiva. Mas, como os bancos estão sujeitos a maiores regulações, o volume de aposta especulativa que estes podem realizar é menor, de modo que no agregado a participação relativa em apostas especulativas seria menor.

Gráfico 20. Posições na BM\&F e a taxa de câmbio

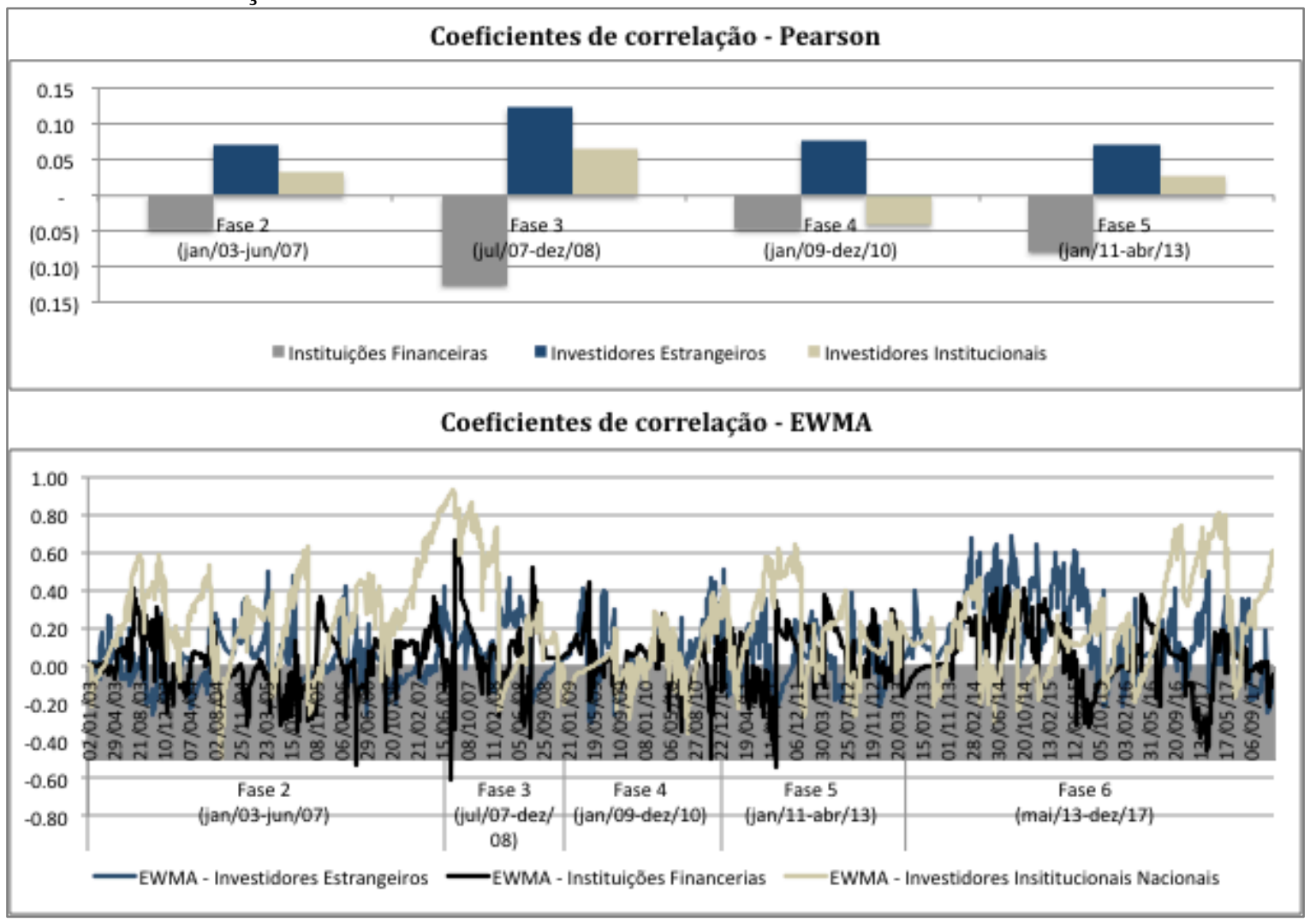

Fonte: BCB (2019), B3 (2019). Elaboração própria.

Ademais, como destaca Farhi (2017), a posição dos bancos no mercado futuro de câmbio brasileiro também pode refletir operações de hedge das suas 
posições nos mercados de balcão onshore e offshore. Porém, as correlações das variações diárias pelo método EWMA não apresentam um resultado tão claro, mas mostra uma ampla variação na correlação das mudanças de posições dos três tipos de investidores e das taxas de câmbio.

\subsection{Taxa de câmbio e índice de commodities}

Como pode ser observado no Gráfico 20, mesmo não tendo majoritariamente produtos primários na sua pauta exportadora, o coeficiente de correlação entre o movimento da taxa de câmbio mexicana e dos preços das commodities, aproximado pelo índice calculado pela Bloomberg, foi elevado e negativo em quase todas as fases analisadas, o que está relacionado à importância do petróleo para a acumulação de reservas na economia mexicana. No Brasil, o coeficiente de correlação negativo se tornou mais elevado a partir da fase 2 .

Gráfico 21. Correlação entre o Índice de commodities e das taxas de câmbio

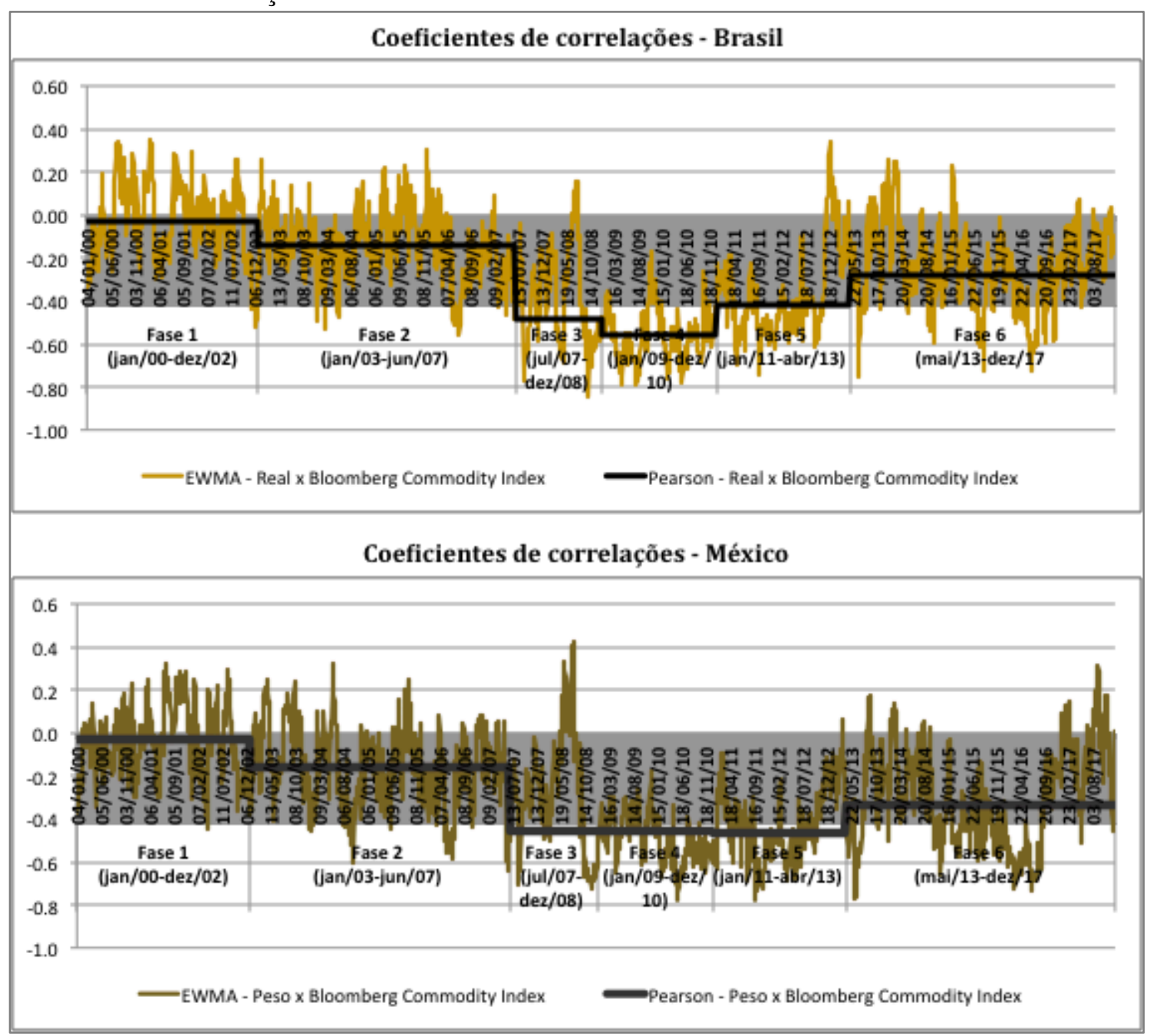

Fonte: BCB (2019), BM (2019), Bloomberg (2019). Elaboração própria. 
No México, o índice de preços das commodities apresentou uma correlação relevante com os fluxos comerciais apenas durante as fases 3 e 6 . Nesses dois períodos, elevações nos preços das commodities estavam associadas a elevações nesses fluxos. Já os fluxos financeiros apresentaram correlação positiva com os preços desses produtos durantes as fases 4, 5 e 6 . Porém, a correlação dos fluxos financeiros com o índice analisado só foi maior do que o coeficiente dos fluxos comerciais em dois períodos (fase 4 e 5), como mostra o gráfico 21.

Já no Brasil o coeficiente de correlação dos fluxos comerciais com os preços das commodities só foi maior do que o dos fluxos financeiros durante a fase 2. Já os aumentos nesses preços estiveram associados à maior entrada de fluxos financeiros durante todas as fases analisadas. Assim, há indícios de que, de fato, o canal de transmissão dos preços das commodities se deu por canais indiretos, como argumentado por Gallagher e Prates (2016).

Gráfico 22. Correlação entre os fluxos e índice de commodities

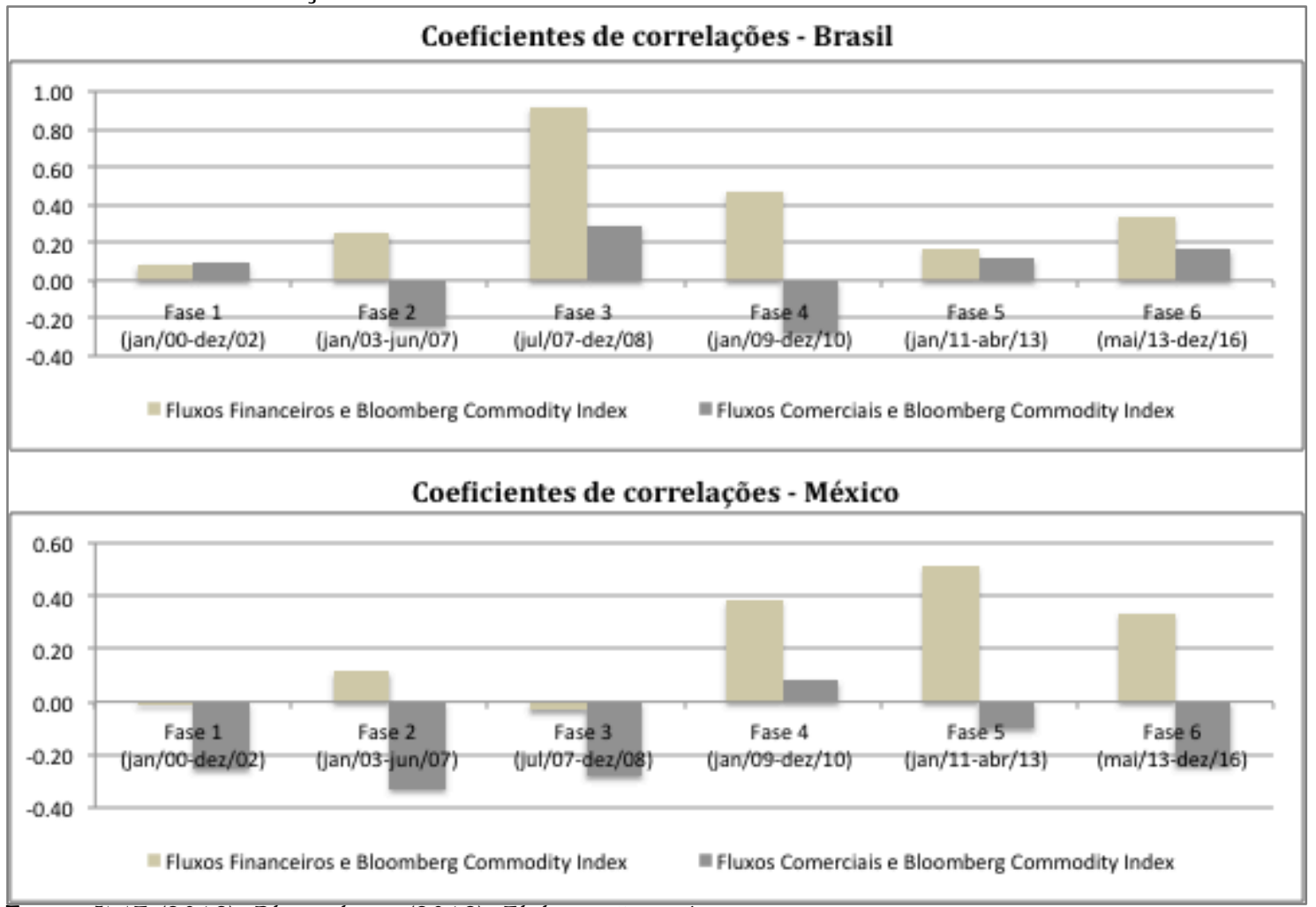

Fonte: IMF (2019), Bloomberg (2019). Elaboração própria. 


\section{Conclusões}

Apesar das taxas de câmbio dos países estudados apresentarem um comovimento similar em todo o período analisado, há diferenças em relação à sua volatilidade e ao impacto dos condicionantes externos, que podem ser explicadas por características institucionais distintas nos dois países. De modo geral, a taxa de câmbio brasileira é mais volátil e, enquanto a moeda brasileira apresentou apreciações e depreciações acima de 7\%, a mexicana só apresentou depreciações dessa magnitude.

Devido às restrições ao endividamento de não residentes em moeda nacional e ao baixo grau de conversibilidade interna da moeda brasileira, o segundo e, especialmente, o terceiro nível de abertura são menores no Brasil do que no México. Esta divergência gera importantes diferenças no mercado cambial entre os dois países estudados. Os menores controles sobre a moeda mexicana tornaram seu mercado à vista mais líquido e permitiram sua internacionalização mais acelerada. Isto, junto com o seu baixo diferencial de juros, tem feito desta moeda uma proxy para operações com outras moedas emergentes. Os menores controles também podem explicar a maior volatilidade dos fluxos de saídas do balanço de pagamentos mexicano. Ademais, a maior internacionalização da moeda mexicana também a torna mais vulnerável às posições dos agentes financeiros no mercado de derivativos offshore.

Já o elevado diferencial de juros brasileiro, ao estimular operações de carry trade potencialmente mais rentáveis, resultam em apreciações mais frequentes do que no caso da moeda mexicana, assim como numa relação, no geral, mais estreita entre as taxas de câmbio e juros. Dada a importância do canal de transmissão da taxa de câmbio para a política monetária em ambos os países elevações da taxa de juros podem ser realizadas com o objetivo de atrair capitais e valorizar a moeda doméstica. Porém, ao contrário do Brasil, o México possui uma receita recorrente em moeda estrangeira devido à regulação sobre as receitas em dólares da PEMEX, que pode reduzir a necessidade de atrair capitais externos mediante o aumento da taxa de juros, em momentos de elevação no preço do petróleo e/ou de elevada produção da PEMEX. Em contrapartida, a taxa de juros mexicana apresentou um comportamento mais volátil do que a brasileira, de modo que a diferença entre a volatilidade cambial das duas moedas não parece ser explicada pela maior volatilidade de juros.

Por outro lado, em função, principalmente, da institucionalidade do mercado de câmbio brasileiro, o mercado de derivativos é mais líquido do que o mercado à 
vista, fazendo com que as posições dos agentes em derivativos cambiais (que tendem a ser mais voláteis) sejam mais relevantes do que os fluxos de divisas para explicar a dinâmica cambial. Desse modo, a maior volatilidade da taxa de câmbio brasileira pode ser explicada pela maior relevância do mercado de derivativos cambiais e pelo elevado patamar da taxa de juros no Brasil, que tem contribuído para depreciações e apreciações mais bruscas. Finalmente, a análise da correlação entre o índice de commodities e os fluxos comerciais e financeiros sugere que a transmissão dos movimentos desses preços para as taxas de câmbio nem sempre se dá pelo canal direto e tradicional da balança comercial. Assim, apesar dos determinantes teóricos apontarem uma elevada correlação com ambas as taxas de câmbio estudadas, as características institucionais particulares que influenciam os tipos de fluxos financeiros e o tamanho e instrumentos utilizados nos mercados de derivativos também exercem influência na dinâmica cambial.

\section{Referências}

Andrade, R. P., \& Prates, D. M. (2013). Exchange rate dynamics in a peripheral monetary economy. Journal of Post Keynesian Economics, 35(3), 399-416. https://doi.org/10.2753/PKE0160-3477350304

B3 - Brasil Bolsa Balcão. (2019). Market data e Índices. São Paulo: B3 - Brasil, Bolsa Balcão. Disponível em http://www.b3.com.br/pt_br/

BCB - Banco Central do Brasil. (2019). Sistema gerenciador de séries temporais. Brasilia: Banco Central do Brasil. Disponível em https://www.bcb.gov.br

BIS - Bank for International Settlement (2015). Currency carry trades in Latin America. Basel, Switzerland. Disponível em https://www.bis.org/publ/bppdf/bispap81.pdf

BIS - Bank for International Settlement (2007). Triennial Central Bank Survey Foreign exchange and derivatives market activity in 2007. Disponivel em: https://www.bis.org/publ/rpfxf07t.htm

BIS - Bank for International Settlement (2010). Triennial Central Bank Survey Foreign exchange and derivatives market activity in 2010. Disponível em: https://www.bis.org/publ/rpfxf10t.htm

BIS - Bank for International Settlement (2013). Triennial Central Bank Survey Foreign exchange and derivatives market activity in 2013. Disponivel em: https://www.bis.org/publ/rpfx13.htm 
BIS - Bank for International Settlement (2016). Triennial Central Bank Survey Foreign exchange and derivatives market activity in 2016. Disponivel em: https://www.bis.org/publ/rpfx16.htm

Bresser-Pereira, L. C. (2009). A tendência da taxa de câmbio à sobrevalirização. In Globalização e competição (pp. 119 - 140). Rio de Janeiro: Campus-Elsevier.

Bloomberg (2019). Bloomberg Terminal. New York: Bloomberg. Disponível em https://www.bloomberg.com/professional/solution/bloomberg-terminal/

BM - Banco de México. (2019). Estadísticas. Ciudad de México: Banco de México. Disponível em https://www.banxico.org.mx

Brooks, C., \& Chong, J. (2001). The Cross-Currency Hedging Performance of Implied Versus Statistical Forecasting Models. Journal of Futures Markets, 21(11), 1043-1069. https://doi.org/10.1002/fut.2104

Capraro, S. (2015). Política monetaria y salario mínimo en México: una visión crítica. In M. A. Mancera (Ed.), Del Salario Mínimo al Salario Digno (pp. 55-104). Ixtapaluca, Estado de México: Consejo Econômico y Social de la Ciudad de México. Disponível em https://seminariorepensarlaeconomia.files.wordpress.com/ 2017/05/libro-del-salario-minimo-al-salario-digno.pdf

Carrasco, C. A., \& Ferreiro, J. (2013). Inflation targeting in Mexico. Journal of Post Keynesian Economics, 35(3), 341-372. https://doi.org/10.2753/PKE01603477350302

CEPALSTAT. (2019). Bases de Datos y Publicaciones Estadísticas. Santiago do Chile: CEPAL (Comissão Econômica para América Latina e Caribe); ONU (Organização das Nações Unidas). Disponível em https://estadisticas.cepal.org/ cepalstat/Portada.html

CME Group - Chicago Mercantile Exchange. (2019). Data. Chicago: CME Group. Disponivel em https://www.cmegroup.com

Collier, D. (1993). The comparative method. In A. W. Finifter (Ed.), Political Science: The State of Discipline II (v. 2, pp. 105-120). Washington, DC: American Political Science Association.

Correa, E. (2014). Mexico's Financial Reforms: Bank Credit Without a Single Currency. International Journal of Political Economy, 43(2), 47-60. https://doi.org/10.2753/IJP0891-1916430203 
Coudert, V., \& Gex, M. (2010). Contagion inside the credit default swaps market: The case of the GM and Ford crisis in 2005. Journal of International Financial Markets, Institutions and Money, 20(2), 109-134. https://doi.org/10.1016/j.intfin.2010.01.001

Farhi, M. (2017). Foreign exchange derivatives and financial fragility in Brazil. In P. Arestis, C. Baltar, \& D. Prates (Eds.), The Brazilian Economy since the Great Financial Crisis of 2007/2008 (pp. 307-335). Palgrave Macmillan, Cham. https://doi.org/10.1007/978-3-319-64885-9_12

FED - Federal Reserve System. (2019). Data. Washington, DC: Board of Governors of the Federal Reserve System. Disponível em https://www.federalreserve.gov/ data.htm

Ferreira, M. A., \& Lopez, J. A. (2005). Evaluating interest rate covariance models within a value-at-risk framework. Journal of Financial Econometrics, 3(1), 126-168. https://doi.org/10.1093/jjfinec/nbi005

FMI, Fundo Monetário Internacional (2018) - Annual Report on Exchange Arrangements and Exchange Restrictions. International Monetary Fund. Monetary and Capital Markets Department. Disponivel em: https://www.imf.org/en/Publications/

Annual-Report-on-Exchange-Arrangements-and-

ExchangeRestrictions/Issues/

2019/04/24/Annual-Report-on-Exchange-Arrangements-and-Exchange-

Restrictions-2018-46162

Gallagher, K. P., \& Prates, D. M. (2016). New Developmentalism versus the Financialization of the Resource Curse. In B. R. Schneider (Ed.), New Order and Progress (pp. 78-104). Oxford University Press. https://doi.org/10.1093/acprof:oso/9780190462888.003.0004

George, A., \& Bennett, A. (2005). Case Studies and Theory Development in the Social Sciences. Cambridge, Massachussets: MIT Press.

Harvey, J. T. (2008). Currencies, capital flows and crises: A post Keynesian analysis of exchange rate determination. Currencies, Capital Flows and Crises: A Post Keynesian Analysis of Exchange Rate Determination. London: Routledge. https://doi.org/10.4324/9780203884782 
He, D., \& McCauley, R. N. (2012). Offshore Markets for the Domestic Currency: Monetary and Financial Stability Issues. SSRN Electronic Journal. Washington, DC. https://doi.org/10.2139/ssrn.1699740

IIF - International Institute of Finance. (2019). IIF Data and Indicators. Washington, DC: International Institute of Finance. Disponível em https://www.iif.com/Research/Data

IMF - International Monetary Fund. (2019). IMF data. Washington, DC: International Monetary Fund. Disponível em https://data.imf.org/

Kaltenbrunner, A. (2015). A post Keynesian framework of exchange rate determination: a Minskyan approach. Journal of Post Keynesian Economics, 38(3), 426-448. https://doi.org/10.1080/01603477.2015.1065678

King, M. R. \& Mallo, C. (2010). A user's guide to the Triennial Central Bank Survey of foreign exchange market activity. BIS Quarterly Review, December. Disponível em: https://www.bis.org/publ/qtrpdf/r_qt1012h.htm

Kohlscheen, E. (2014). Long-run determinants of the brazilian real: A closer look at commodities. International Journal of Finance and Economics, 19(4), 239250. https://doi.org/10.1002/ijfe.1493

Mohanty, M., \& Scatigna, M. (2005). Has globalisation reduced monetary policy independence? In Globalisation and monetary policy in emerging markets (n. 23, pp. 17-58). Basel, Switzerland: BIS papers.

OECD (2015). OECD Economic Surveys: Brazil 2015. Paris: OECD. https://doi.org/10.1787/eco_surveys-bra-2015-en

OECD. (2017). OECD Economic Surveys: Mexico 2017. Paris: OECD. https://doi.org/10.1787/eco_surveys-mex-2017-en

Prates, D. (2002). Crises financeiras dos países "emergentes": uma interpretação heterodoxa. Tese de Doutorado - Universidade Estadual de Campinas Campinas.

Disponível

em http://www.repositorio.unicamp.br/handle/REPOSIP/285473

Prates, D. (2010). O regime cambial brasileiro de 1999 a 2008. Brasilia, DF: CEPAL. Disponivel em http://www.ipea.gov.br/portal/images/stories/PDFs/TDs /td_1530.pdf

Prates, D. (2015). O regime de câmbio flutuante no Brasil: 1999 - 2012: especificidades e dilemas. Brasilia: IPEA. Disponível em 
http://repositorio.ipea.gov.br/

bitstream/11058/3901/1/O regime de câmbio flutuante no Brasil_19992012.pdf

Ramos, R. (2016). Financialization and its Implications on the Determination of Exchange Rates of Emerging Market Economies. Tese de Doutorado, Universidade Estadual de Campinas e Université Paris 13. Disponível em http://repositorio.unicamp.br/handle/REPOSIP/332042

Ramos, R. M., \& Prates, D. (2018). Heterodox Exchange Rate Theories: towards the consolidation of the different contributions and its presentation in the ABSFC framework (unpublished).

Ros, J. (2015). Central Bank Policies in Mexico: Targets, instruments, and performance. Comparative Economic Studies, 57(3), 483-510. https://doi.org/10.1057/ces.2015.6

Rossi, P. (2016). Taxa de câmbio e política cambial no Brasil: teoria, institucionalidade, papel da arbitragem e da especulação (1a ed.). Rio de Janeiro: Editora FGV.

Schulmeister, S. (1987). An Essay on Exchange Rate Dynamics (No. 0722-673X). Vienna: Wissenschaftszentrum. https://doi.org/10.2139/ssrn.1714333

Serrano, F. (2010). Juros, câmbio e o sistema de metas de inflação no Brasil. Revista de Economia Politica, 30(1), 63-72. https://doi.org/10.1590/s010131572010000100004

Sidaoui, J. (2005). Central banking intervention under a floating exchange rate regime: ten years of Mexican experience. In Foreign exchange market intervention in emerging markets: motives, techniques and implications (pp. 209-230). Basel, Switzerland: Bank for International Settlements. Disponível em https://www.bis.org/publ/bppdf/bispap24r.pdf

Tornell, A., Westermann, F., \& Martínez, L. (2003). Liberalization, growth and financial crises: Lessons from Mexico and the developing world. Brookings Papers on Economic Activity, 2, 112. Disponível em https://www.brookings.edu/wp-content/uploads/2003/06/2003b_bpea_ tornell.pdf

Ventura, A., \& Garcia, M. (2012). Mercados futuro e à vista de câmbio no Brasil: $\bigcirc$ rabo abana o cachorro. Revista Brasileira de Economia, 661), 21-48. https://doi.org/10.1590/S0034-71402012000100002 